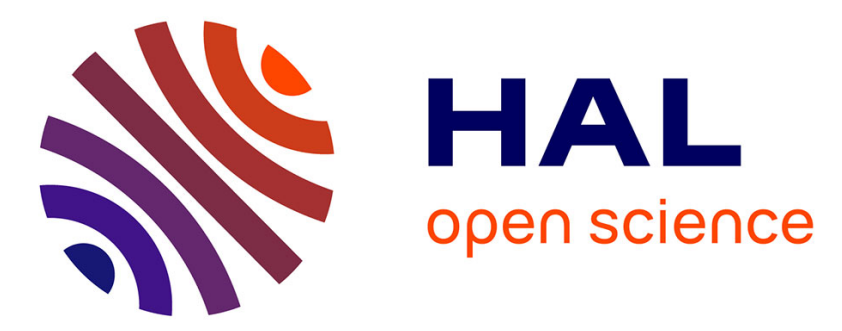

\title{
Overriding plate thinning in subduction zones: Localized convection induced by slab dehydration
}

D. Arcay, M.-P. Doin, E. Tric, R. Bousquet, C. de Capitani

\section{To cite this version:}

D. Arcay, M.-P. Doin, E. Tric, R. Bousquet, C. de Capitani. Overriding plate thinning in subduction zones: Localized convection induced by slab dehydration. Geochemistry, Geophysics, Geosystems, 2006, 7, pp.Q02007. 10.1029/2005GC001061 . hal-00407579

\section{HAL Id: hal-00407579 \\ https://hal.science/hal-00407579}

Submitted on 20 Dec 2021

HAL is a multi-disciplinary open access archive for the deposit and dissemination of scientific research documents, whether they are published or not. The documents may come from teaching and research institutions in France or abroad, or from public or private research centers.
L'archive ouverte pluridisciplinaire HAL, est destinée au dépôt et à la diffusion de documents scientifiques de niveau recherche, publiés ou non, émanant des établissements d'enseignement et de recherche français ou étrangers, des laboratoires publics ou privés.

$$
\text { Copyright }
$$




\title{
Overriding plate thinning in subduction zones: Localized convection induced by slab dehydration
}

\author{
D. Arcay \\ Laboratoire Géosciences Azur, Université de Nice-Sophia Antipolis, 250 Rue Albert Einstein, F-06560 Valbonne, \\ France(arcay@geoazur.unice.fr)
}

\author{
M.-P. Doin \\ Laboratoire de Géologie, Ecole Normale Supérieure, 24 Rue Lhomond, F-75231 Paris Cedex 05, France \\ (doin@geologie.ens.fr)
}

E. Tric

Laboratoire Géosciences Azur, Université de Nice-Sophia Antipolis, 250 Rue Albert Einstein, F-06560 Valbonne, France(tric@geoazur.unice.fr)

\author{
R. Bousquet \\ Institut für Geowissenschaften, Universität Potsdam, Karl Liebnechtstrasse 24-25, D-14476 Potsdam-Golm, Germany \\ (romain@geo.uni-potsdam.de)
}

\section{C. de Capitani}

\author{
Mineralogisch-Petrographisches Institut, Universität Basel, Bernoullistrasse 30, CH-4056 Basel, Switzerland \\ (christian.decapitani@unibas.ch)
}

[1] In subduction zones, many observations indicate that the backarc thermal state is particularly hot and that the upper lithosphere is thin, even if no recent extension episode has occurred. This might result from free thermal convection favored by low viscosities in the hydrated mantle wedge. We perform 2-D numerical experiments of the convective mantle wedge interaction with both the downgoing slab and the overriding plate to test this hypothesis, explore its physical mechanism, and assess its dependencies on some relevant rock properties. Water transfers across the subducting plate and the mantle wedge are explicitly modeled by including in the calculation realistic hydration/dehydration reaction boundaries for a water-saturated mantle and oceanic crust. The rheology is non-Newtonian and temperature-, pressure-, and water content-dependent. For low strength reduction associated to water content, the upper plate is locally thinned by an enhanced corner flow. For larger strength reductions, small convection cells rapidly thin the upper plate (in less than $15 \mathrm{Myr}$ ) over the area in the overriding lithosphere hydrated by slab-derived water fluxes. As a result, the thinned region location depends on the subducting plate thermal state, and it increases with high convergence rates and low subduction dip angles. Other simulations are performed to test the sole effect of hydrous rock weakening on the upper plate/mantle convective interaction. They show that the thinning process is not influenced by the corner flow, but develops at the favor of a decoupling level induced by the formation of hydroxylated minerals inside the hydrated lithosphere. The erosion mechanism identified in these simulations allows us to explain the characteristic duration of erosion as a function of the hydrous strength reduction. We find that the presence of amphibole in the upper lithosphere in significant proportions is required down to a temperature of about $980^{\circ} \mathrm{C}$, corresponding to an initial depth of $\sim 70 \mathrm{~km}$, to strongly decrease the strength of the base of the lithosphere and trigger a rapid erosion $(<15 \mathrm{Myr})$. 
Components: 9137 words, 12 figures, 3 tables.

Keywords: dehydration; hydration; subduction; thermal convection.

Index Terms: 8121 Tectonophysics: Dynamics: convection currents, and mantle plumes; 8120 Tectonophysics: Dynamics of lithosphere and mantle: general (1213); 8170 Tectonophysics: Subduction zone processes (1031, 3060, 3613, 8413).

Received 30 June 2005; Revised 3 October 2005; Accepted 21 November 2005; Published 10 February 2006.

Arcay, D., M.-P. Doin, E. Tric, R. Bousquet, and C. de Capitani (2006), Overriding plate thinning in subduction zones: Localized convection induced by slab dehydration, Geochem. Geophys. Geosyst., 7, Q02007, doi:10.1029/2005GC001061.

\section{Introduction}

[2] Currie et al. [2004a] argue that the upper plate thermal state in subduction zones is especially hot not only beneath the volcanic arc, but also below the backarc region, even if no recent extension has been recorded. The thermal structures of six backarcs which did not undergo extension for $50 \mathrm{Myr}$ (Northern Cascadia, Mexico/Central America, South America, Alaska/Eastern Aleutians, Kamchatka, and Sunda) have been investigated by combining different independent approaches [Wanatabe et al., 1977; Springer and Forster, 1998; Currie et al., 2004b]. In all cases, the temperature at a depth of $60 \mathrm{~km}$ is close to $1200^{\circ} \mathrm{C}$, a few hundreds of kilometer away from the arc [Currie et al., 2004b]. Specific explanations for each site could be invoked, but this feature common to many subduction zones suggests that it results from a phenomenon closely related to the subduction process itself.

[3] Vigorous corner flow in the mantle wedge has been proposed to warm the overriding plate [McKenzie, 1969; Andrews and Sleep, 1974; Eberle et al., 2002; Kelemen et al., 2003] and suggested as a triggering factor of the arc magmatism [Kelemen et al., 2003; Currie et al., 2004a]. However, the lithospheric heating induced by the slab driven asthenospheric flow remains always localized in the wedge tip and cannot account for the hot thermal structure below the backarc. Thermal convection, intensified by low rock viscosities, was then proposed to explain the overriding plate thermal state [Honda et al., 2002; Currie et al., 2004a, 2004b; Hyndman et al., 2005]. Asthenospheric viscosities are likely to be decreased by the water released by the subducting lithosphere [Hirth and Kohlstedt, 1996]. Hence convection in the mantle wedge could be triggered by the subducting slab dehydration [Arcay et al., 2005].
[4] Seismic wave high attenuation patches, which are correlated with volcano distribution in NE Japan, have a 3-D pattern, that might be the signature of mantle wedge convection [Tsumura et al., 2000]. This is also suggested by the horizontal heterogeneity of temperature underneath NE Japan [Hasegawa et al., 2000]. Three-dimensional modeling of convection in a low viscosity wedge have been performed to reproduce along-arc thermal heterogeneities underneath NE Japan [Honda et al., 2002], and to study the influence of the properties of the low viscosity wedge on the convective flow [Honda and Saito, 2003]. Honda and Yoshida [2005] also perform 3-D simulations to model the backarc thermal state in NE Japan and the volcano distribution time evolution, but without computing water transfers during subduction. Even if the mantle wedge structure is likely to be three dimensional, 2-D simulations are useful to increase the model accuracy with realistic upper lithosphere/slab wedge structures.

[5] Other numerical models of subduction include slab dehydration to study the exhumation processes of high pressure metamorphic rocks [Gerya et al., 2002], and the formation of cold and buoyant diapirs rising from the slab surface [Gerya and Yuen, 2003; Gerya et al., 2004]. This modeling simulates density changes related to both water content and partial melting degree variations, which locally invert flow direction in the mantle wedge. However, in this model, the horizontal extent of the slab dehydration area is imposed as a boundary condition, which limits the study of the thermomechanical coupling between the hydrated mantle wedge and the overlying plate. Arcay et al. [2005] develop an explicit slab dehydration-mantle wedge hydration model based on accurate phase diagrams. This water transfer model is included into a thermochemical convection model of subduction, and takes into account a water content- 


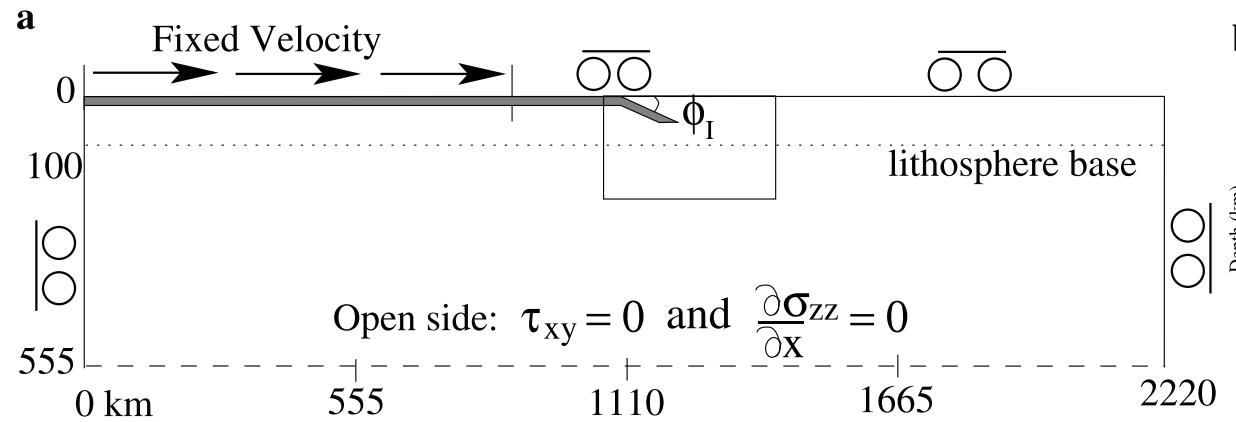

b

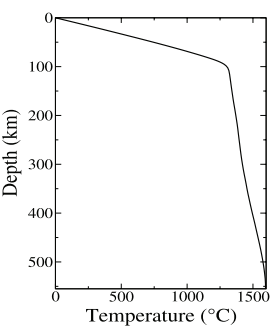

Figure 1. (a) Mechanical boundary conditions and initial state geometry. The black box in the center of the subduction zone delimits the zoom displayed in Figure 4 and in Figure 12. (b) Initial geotherm.

dependence of rheology. When the subducting plate dehydrates, the overlying mantle, that can only dissolve very low amounts of water, is instantaneously water-saturated and the remaining water is absorbed by the overriding lithosphere. For sufficient strength reductions associated to water content, convection cells in the mantle wedge develop and rapidly thin the upper lithosphere, on a 100-150 km wide region [Arcay et al., 2005]. In this paper, we refer as "erosion" the thermal thinning of the upper plate. The erosion of the upper lithosphere obtained in these simulations cannot be directly compared to classical smallscale convection. The present paper motivations are to quantify the speed and conditions for the upper plate thinning process, to study how the wedge flow modifies the convective erosion pattern, and finally to constrain the physical mechanism at the origin of upper plate rapid thinning. This is presented after a summary of the model setup.

\section{Model Setup}

[6] We perform 2-D numerical simulations solving the conservation equations of energy, mass, and momentum, in the extended Boussinesq approximation. Rocks are assumed to be incompressible, but the buoyancy forces due to rock thermal expansion are included in the Stokes equation. Besides, we take into account in the energy equation both dissipation heating and adiabatic heating terms. The model includes various rock chemical compositions (crust, mantle, and water content), that differ in density and rheology. They are tracked numerically by tracers advected with the velocity field. In the following, we briefly present the subduction geometry and boundary conditions, the rheology, and the model for water transfers. A complete discussion on model assumptions and choices is given by Arcay et al. [2005].

\subsection{Subduction Geometry and Initial State}

\subsubsection{Subduction Model}

[7] We model oceanic subduction on a $2220 \mathrm{~km}$ wide and $555 \mathrm{~km}$ deep box (Figure 1a). Lithospheric and asthenospheric mantle have the same peridotite composition. The subducting lithosphere is covered by a $7 \mathrm{~km}$ thick oceanic crust layer. The overriding plate is not overlain by a crustal layer, unless stated in one case in Table 1. We enforce subduction by combining two mechanical conditions. First, we fix a constant velocity on the side of the converging plate far from the trench (Figure 1a). Second, we impose an initial subduction plane geometry by including a $7 \mathrm{~km}$ thick panel of oceanic crust, dipping into the lithosphere, with an angle $\phi$, fixed to either to $30^{\circ}, 15^{\circ}$, or $60^{\circ}$. As crustal rocks are weaker than mantle ones (see section 2.3), this plane localizes deformations and allows subduction initiation [Doin and Henry, 2001]. As convergence goes on, crustal materials continue to flow along the subduction plane and help maintaining localized bending. The subduction plane dip then evolves freely.

\subsubsection{Thermal and Mechanical Boundary Conditions}

[8] Along the surface, the temperature is set to $0^{\circ} \mathrm{C}$, whereas across all other boundaries thermal gradients are equal to zero. Rocks in the whole box are heated by a uniform radiogenic source (see Table 2). The initial thermal thickness of the subducting and overriding plates is about $100 \mathrm{~km}$ at the onset of subduction. The initial mantle and lithosphere thermal structure is the result of a preliminary simulation, in which lithospheric ther- 
Table 1. Subduction Simulation List ${ }^{\mathrm{a}}$

\begin{tabular}{|c|c|c|c|c|}
\hline Simulation & $\begin{array}{c}\text { Convergence Rate } \\
v, \mathrm{~cm} / \mathrm{yr}\end{array}$ & $\begin{array}{c}\text { Initial Dip Angle } \\
\qquad,,^{\circ}\end{array}$ & $\begin{array}{l}\text { Hydrous Strength } \\
\text { Reduction } f_{v}\end{array}$ & $\begin{array}{c}{\left[\mathrm{OH}^{-}\right] \text {-Grid for }} \\
\text { Peridotite }\end{array}$ \\
\hline S1a & 5.3 & 30. & 1. & SP \\
\hline S1b & 10. & 30. & 1. & SP \\
\hline S1c & 2. & 30. & 1. & SP \\
\hline $\mathrm{S} 2 \mathrm{a}$ & 5.3 & 30. & 5. & SP \\
\hline $\mathrm{S} 2 \mathrm{~b}$ & 5.3 & 30. & 10. & SP \\
\hline $\mathrm{S} 2 \mathrm{~b} 2^{\mathrm{b}}$ & 5.3 & 30. & 10. & SP \\
\hline $\mathrm{S} 2 \mathrm{c}^{\mathrm{b}, \mathrm{c}}$ & 5.3 & 30. & 20. & SP \\
\hline $\mathrm{S} 2 \mathrm{~d}$ & 5.3 & 30. & 50. & SP \\
\hline $\mathrm{S} 2 \mathrm{e}$ & 5.3 & 30. & 100. & SP \\
\hline S2f & 5.3 & 30. & 1000. & SP \\
\hline $\mathrm{S} 3 \mathrm{a}$ & 2. & 30. & 50. & SP \\
\hline $\mathrm{S} 3 \mathrm{~b}$ & 7. & 30. & 50. & SP \\
\hline $\mathrm{S} 3 \mathrm{c}$ & 10. & 30. & 50. & SP \\
\hline $\mathrm{S} 4 \mathrm{a}$ & 5.3 & 15. & 50. & SP \\
\hline $\mathrm{S} 4 \mathrm{~b}$ & 5.3 & 60. & 50. & SP \\
\hline $\mathrm{S} 5 \mathrm{a}$ & 5.3 & 30. & 50. & $\mathrm{BC}$ \\
\hline $\mathrm{S} 5 \mathrm{~b}$ & 5.3 & 30. & 100. & $\mathrm{BC}$ \\
\hline
\end{tabular}

${ }^{\mathrm{a}} \mathrm{SP}$, Schmidt and Poli [1998]; BC, this study.

${ }^{\mathrm{b}}$ These two simulations are performed on a 6 aspect ratio box (see section 2.1.2).

${ }^{\mathrm{c}}$ Performed with an oceanic crustal layer at the surface of the overriding plate.

mal equilibrium between cooling from above and heating from below is obtained without plate tectonics (Figure 1b). The thermomechanical parameters used in this preliminary simulation are otherwise identical to those used in subduction experiments (Table 2). The lithosphere thermal base is characterized by small thermal anomalies, with amplitudes lower than $100^{\circ} \mathrm{C}$, that result from

Table 2. Parameter Names and Values

\begin{tabular}{|c|c|c|}
\hline Parameter Name & Symbol & Value \\
\hline Box height & $H_{0}$ & $555 \mathrm{~km}$ \\
\hline Bottom temperature & $T_{b}$ & $1888 \mathrm{~K}$ \\
\hline Surface temperature & $T_{s}$ & $273 \mathrm{~K}$ \\
\hline Asthenosphere temperature & $T_{a}$ & $1623 \mathrm{~K}$ \\
\hline Mantle density & $\rho_{m}$ & $3300 \mathrm{~kg} \cdot \mathrm{m}^{-3}$ \\
\hline Crustal density & $\rho_{c}$ & $2920 \mathrm{~kg} \cdot \mathrm{m}^{-3}$ \\
\hline Radiogenic heat production & $A$ & $9.20 \times 10^{-8} \mathrm{~W} \cdot \mathrm{m}^{-3}$ \\
\hline Thermal diffusivity & $\kappa$ & $0.8 \times 10^{-6} \mathrm{~m}^{2} \cdot \mathrm{s}^{-1}$ \\
\hline Thermal conductivity & $k$ & $2.56 \mathrm{~W} \cdot \mathrm{m}^{-1} \cdot \mathrm{K}^{-1}$ \\
\hline Thermal expansion coefficient & $\alpha$ & $3.5 \times 10^{-5} \mathrm{~K}^{-1}$ \\
\hline Heat capacity & $C_{p}$ & $0.971 \times 10^{3} \mathrm{~J} .(\mathrm{K} . \mathrm{kg})^{-1}$ \\
\hline Gravity acceleration & $g$ & $9.81 \mathrm{~m} \cdot \mathrm{s}^{-2}$ \\
\hline Oceanic crust thickness & $\stackrel{\circ}{H}_{c}$ & $6.9 \mathrm{~km}$ \\
\hline Preexponential constant for the "dry" viscous rheology & $A_{0}{ }^{d r y}$ & $53280 \mathrm{~Pa} \cdot \mathrm{s}^{\frac{1}{3}}$ \\
\hline Activation energy in the mantle & $E_{a}^{m}$ & $395 \mathrm{~kJ} \cdot \mathrm{mol}^{-1}$ \\
\hline Activation energy in the crust & $E_{a}{ }^{c}$ & $285 \mathrm{~kJ}^{\mathrm{mol}} \mathrm{mol}^{-1}$ \\
\hline Activation volume & $V_{a}$ & $2.34 \times 10^{-5} \mathrm{~m}^{3} \cdot \mathrm{mol}^{-1}$ \\
\hline Gas constant & $R$ & $8.32 \mathrm{~J} .(\mathrm{mol} . \mathrm{K})^{-1}$ \\
\hline Cohesive strength & $\tau_{0}$ & $1 \mathrm{MPa}$ \\
\hline Stress exponent in the viscous rheology & $n$ & 3 \\
\hline Stress exponent in the brittle rheology & $n_{p}$ & 30 \\
\hline Reference strain rate & $\dot{\varepsilon}_{r e f}$ & $10^{-14} \mathrm{~s}^{-1}$ \\
\hline Yield stress increase with depth (crust) & $\gamma_{c}$ & 0.06 \\
\hline Yield stress increase with depth (mantle) & $\gamma_{m}$ & 1.5 \\
\hline Hydrous strength reduction & $f_{v}$ & $1-1000$ \\
\hline
\end{tabular}



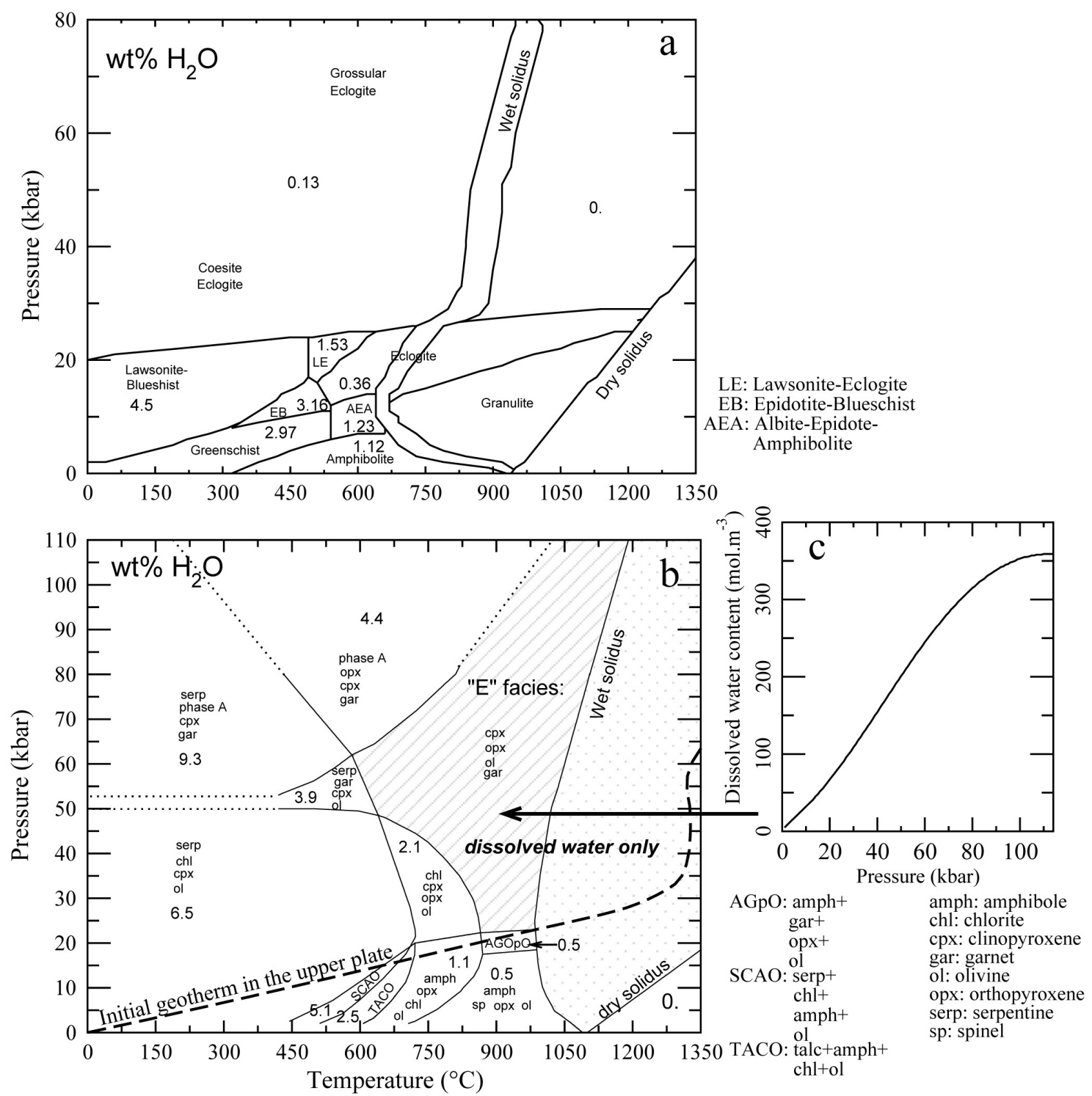

Figure 2. Phase diagrams and corresponding water contents used to perform water transfers during subduction. (a) Metamorphic facies and water content (\% wt) for gabbro, after Bousquet et al. [1997]. (b) Water content in weight percent for a $\mathrm{H}_{2} \mathrm{O}$-saturated peridotite (lherzolite composition), from Schmidt and Poli [1998]. Extrapolation from phase transitions obtained by Schmidt and Poli [1998] are shown with dotted lines. The initial geotherm in the upper lithosphere is displayed with a dashed line. (c) Water solubility in lherzolite as a function of pressure at $1000^{\circ} \mathrm{C}$ in the E facies.

small scale convection. Below the lithosphere, the mantle temperature profile is characterized by an adiabatic gradient equal to $0.445 \mathrm{~K} . \mathrm{km}^{-1}$.

[9] Mechanical boundary conditions are displayed in Figure 1a. The bottom boundary is open to prevent the slab from rolling up when the diving plate reaches the box base. The right side is closed and the convergence velocity is imposed on the left side of the left plate, on a $16 \mathrm{~km}$ thick top layer. Velocity divergence on the left corner then creates a "ridge" filled with hot asthenosphere rocks, directly in contact with the surface. The lithosphere that is newly formed at the ridge cools when it moves toward the right, but still remains thin and hot when it reaches the trench (in $55 \mathrm{Myr}$ for $2 \mathrm{~cm} / \mathrm{yr}$, in $10 \mathrm{Myr}$ for $10 \mathrm{~cm} / \mathrm{yr}$ ). Consequently, the initial lithosphere length located before the trench at the onset of subduction $(1110 \mathrm{~km})$ represents the maximum slab length that can be reached during these subduction experiments. To study the subduction longer-term evolution, two simulations 
are performed on an increased aspect ratio box (6 rather than 4) (simulations S2b2 and S2c in Table 1). In these cases, the trench is fixed $2414 \mathrm{~km}$ away from the left side.

\subsection{Water Transfer Model}

\subsubsection{Phase Diagrams}

[10] Water transfers during subduction are based on two phase diagrams for water-saturated rocks (Figure 2). For mantle rocks and oceanic crust, respectively, we use the lherzolite phase diagram of Schmidt and Poli [1998] and the gabbro phase diagram of Bousquet et al. [1997], respectively. These phase diagrams give the water amount contained within nominally hydrous minerals stable within given $P$ - $T$ ranges.

[11] However, for mantle rocks characterized by temperature larger than $1000^{\circ} \mathrm{C}$ and pressure greater than $22 \mathrm{kbar}(\sim 70 \mathrm{~km})$, no nominally hydrous minerals are stable (facies labelled "E" in Figure $2 \mathrm{~b}$ ), although the four minerals stable in these conditions (olivine, orthopyroxene, clinopyroxene, and garnet) may dissolve water [Kohlstedt et al., 1995; Lu and Keppler, 1997; Rauch and Keppler, 2002]. Using water solubilities as a function of temperature and pressure in olivine, orthopyroxene, and garnet given by Kohlstedt et al. [1995], Rauch and Keppler [2002], and Lu and Keppler [1997], respectively, we deduce the water solubility in the $\mathrm{E}$ facies [Arcay et al., 2005], assuming the lherzolitic composition given by Schmidt and Poli [1998], and a temperature of $1000^{\circ} \mathrm{C}$. We also assume that clinopyroxene dissolves 1.5 times the water amount dissolved by orthopyroxene (H. Keppler, personal communication). Figure $2 \mathrm{c}$ displays the dissolved water amount that we obtain in the $\mathrm{E}$ facies as a function of pressure.

[12] In the partial melting domain, we also add water contents corresponding to the solubility of peridotite in this facies. Water contents are computed in the following way: Along the wet solidus, the water content is assumed to be the dissolved water amount in the $\mathrm{E}$ facies at the same pressure. Along the dry solidus (derived from McKenzie and Bickle [1988]), the water content at the same pressure is set to zero. Between these two values, we impose a linear decrease of $\left[\mathrm{OH}^{-}\right]$as a function of $T$, for a constant pressure.

\subsubsection{Water Contents Before Subduction}

[13] We assume that hydrothermal alteration at the ridge and water circulation along normal faults created by bending near the trench are responsible for a high hydration degree and a hydration maximum depth close to $20 \mathrm{~km}$ in the oceanic lithosphere before subduction. This is discussed by Arcay et al. [2005]. We do not model these lithosphere hydration processes, but impose hydration at the initial state, before subduction starts. The gabbroic layer is supposed to be watersaturated on its $7 \mathrm{~km}$ thickness before entering the trench. The corresponding water content in the Bousquet et al. [1997] phase diagram is $2.97 \mathrm{wt} \%$ (greenschist facies), which is the value we impose for all crustal elements. Below the crust, a $15 \mathrm{~km}$ peridotitic layer, between 7 and $22 \mathrm{~km}$ depth, is assumed to be serpentinized. According to $P-T$ conditions at these depths and the phase diagram in Figure $2 \mathrm{a}$, the water content in this layer is set to $6.5 \mathrm{wt} \%$.

\subsubsection{Water Transfer Simulation}

[14] We compute water transfers using the gabbro phase diagram for phase transitions occurring in the crust, and the lherzolite phase diagram to predict water exchanges in the peridotitic part of the subducting plate, in the mantle wedge, and in the overriding plate. Water content changes are tracked numerically by all rock tracers present in the subduction zone. Each tracer represents a $1 \times$ $1 \mathrm{~km}^{2}$ area and either crustal or mantle rocks. The facies and saturation water content of a tracer vary with its in situ temperature and pressure (Figure 2). If, at a given time step, the saturation water content becomes lower than the tracer water amount at the previous time step, the tracer loses its water in excess. On the contrary, if the saturation water content is larger than the tracer water amount, the tracer is allowed to absorb water, depending on water availability and on the maximum quantity that it can absorb before reaching saturation. If the released water cannot be absorbed by neighboring tracers, it goes up until it meets tracers allowed to absorb water. If, during the water rise, it reaches the hydration minimum depth in the lithosphere (fixed to $11 \mathrm{~km}$ ), it is evaporated. Note that we do not take into account metamorphic reaction kinetics in this model: the time step between two iterations (about 25,000 years) is assumed to be long enough to allow a phase transition completion.

\subsection{Rheology}

[15] The modeled rheology depends on temperature, $T$, depth, $z$, strain rate, $\dot{\varepsilon}$, composition, $C$ (crust or mantle), and water content $\left[\mathrm{OH}^{-}\right]$. The melt 
influence on rheology is not modeled. The deformation mechanism is defined by either a pseudobrittle rheology (viscosity labelled $\nu_{b}$ ) or a viscous non-linear rheology (viscosity labelled $\nu_{v}$ ). In both cases, stress $(\tau)$ and deformation rate $(\dot{\varepsilon})$ are linked through an effective viscosity, $\tau=\dot{\varepsilon} \nu_{\text {eff }}$, where $\tau$ and $\dot{\varepsilon}$, respectively, are second invariants of the deviatoric stress tensor, and strain rate tensor, respectively. The effective viscosity, $v_{\text {eff, finally }}$ writes as: $\nu_{\text {eff }}=\left(1 / \nu_{b}+1 / \nu_{v}\right)^{-1}$.

[16] In the pseudo-brittle domain, the yield stress, $\tau_{y}$, increases with depth as $\tau_{y}=\tau_{0}+\gamma(C) \rho_{m} g z$, where $\tau_{0}$ is the frictional cohesive strength at the surface and $\gamma$ is related to the friction coefficient [Turcotte and Schubert, 1982], that here depends on rock composition. We implement the pseudobrittle rheology through the formula

$$
\dot{\varepsilon}=\left(\frac{\tau}{\tau_{y}}\right)^{n_{p}} \dot{\varepsilon}_{r e f}
$$

where $n_{p}$ is a stress power coefficient $\left(n_{p}=30\right)$ and $\dot{\varepsilon}_{\text {ref }}$ is a reference strain rate (Table 2). The relationship (1) implies very low deformations if $\tau<\tau_{y}$, and very high strain rates as soon as $\tau>\tau_{y}$. The effective viscosity, $\nu_{b}$, in the brittle domain thus writes as:

$$
v_{b}=\tau_{y} \dot{\varepsilon}^{\frac{1}{n_{p}}-1} / \dot{\varepsilon}_{r e f}^{\frac{1}{n_{p}}}
$$

[17] The non-Newtonian viscous rheology is defined by an effective viscosity, $\nu_{v}$ :

$$
\nu_{v}=A_{0}\left(\left[O H^{-}\right]\right) \exp \left(\frac{E_{a}(C)+V_{a} \rho g z}{n R T}\right) \dot{\varepsilon}^{\frac{1}{n}-1}
$$

where $E_{a}$ is the activation energy, $V_{a}$ is the activation volume, $R$ is the gas constant, $n_{v}$ is an exponent equal to 3 , and $A_{0}$ is a preexponential constant depending on the water content, as discussed below. $E_{a}$ is a function of composition, crust or mantle. Because the activation energy is lower for the crust than for the mantle, crustal rocks are weaker than peridotitic rocks. Moreover, we choose a much lower value for the crust friction coefficient than for the mantle one $\left(\gamma_{c}=\right.$ 0.06 and $\gamma_{m}=1.5$, corresponding to a friction coefficient of 0.05 and 0.6 , respectively). Because of the large pressure-dependence of the viscosity, the minimum viscosity layer has a temperature in the range $1350-1400^{\circ} \mathrm{C}$ and defines the asthenosphere. It is located on top of the convective mantle characterized by an adiabatic thermal gradient.
[18] We choose to parameterize the water softening by a decrease in the preexponential factor, $A_{0}$, in equation (2), as a function of the water content, $\left[O H^{-}\right]$:

$$
A_{0}\left(\left[O H^{-}\right]\right)=\frac{A_{0}^{d r y}}{f\left(\left[O H^{-}\right]\right)}
$$

and

$$
f\left(\left[O H^{-}\right]\right)=\left[1-\frac{1}{f_{v}}\right] \exp \left(-\frac{\left[O H^{-}\right]}{\left[\mathrm{OH}_{0}^{-}\right]}\right)+\frac{1}{f_{v}}
$$

where $A_{0}^{d r y}$ is the preexponential factor in equation (2) for a null water content, $f$ is the strength reduction as a function of water content, $\left[\mathrm{OH}_{0}^{-}\right]$is a reference water content $\left(120 \mathrm{~mol} \cdot \mathrm{m}^{-3} \simeq 620 \mathrm{wt}\right.$. $\mathrm{ppm}$ ), and $f_{\nu}$ is the maximum strength reduction induced by the presence of water $\left(A_{0}^{\infty}=A_{0}^{d r y} / f_{v}\right)$. Besides, the strength reduction, $f$, is only applied to mantle rocks. The simple parameterization employed for $f$ is not based on theoretical studies or experimental results. It is designed to impose two different strength reductions depending on how water is absorbed in minerals. (1) When, as in the mantle wedge domain, minerals absorb water only by dissolution, the strength reduction, $f$, depends only slightly on water content, and is always lower than $f_{\nu}$ (between 3.5 if $f_{\nu}=5$, and 7, if $f_{\nu}=1000$, respectively, at a depth of $\sim 200 \mathrm{~km}$, Figure 3). (2) For water contents higher than $0.42 \mathrm{wt} \%$, i.e., for peridotite including nominally hydrous minerals, the water softening effect does not depend on $\left[\mathrm{OH}^{-}\right]$, and is equal to $f_{v}$ (Figure 3). Very few nodes in our model are in the water content interval between cases (1) and (2), for which $f$ varies strongly with water content.

[19] The maximum strength reduction applied for case (1) is $\sim 10$. It can be compared to the viscosity contrast for a given strain rate in olivine inferred from experimental data. The latter is of the order a factor 30 between water-saturated and dry olivine, but only of a factor 3 between a wet and a damp $(\sim 50 \mathrm{ppm})$ olivine [Hirth and Kohlstedt, 1996]. We are not aware of experiments focussing on the strength reduction associated with the formation of hydrous minerals in peridotite. However, observations of strain localization in natural mafic rocks show that shearing quite often localizes preferentially in more mafic pyroxene- and amphibole-rich layers rather than in the plagioclase- and feldsparrich wall rocks [Altenberger, 1997], even if the monominerals of plagioclase and feldspar are weaker than pyroxene or amphibole. This is prob- 


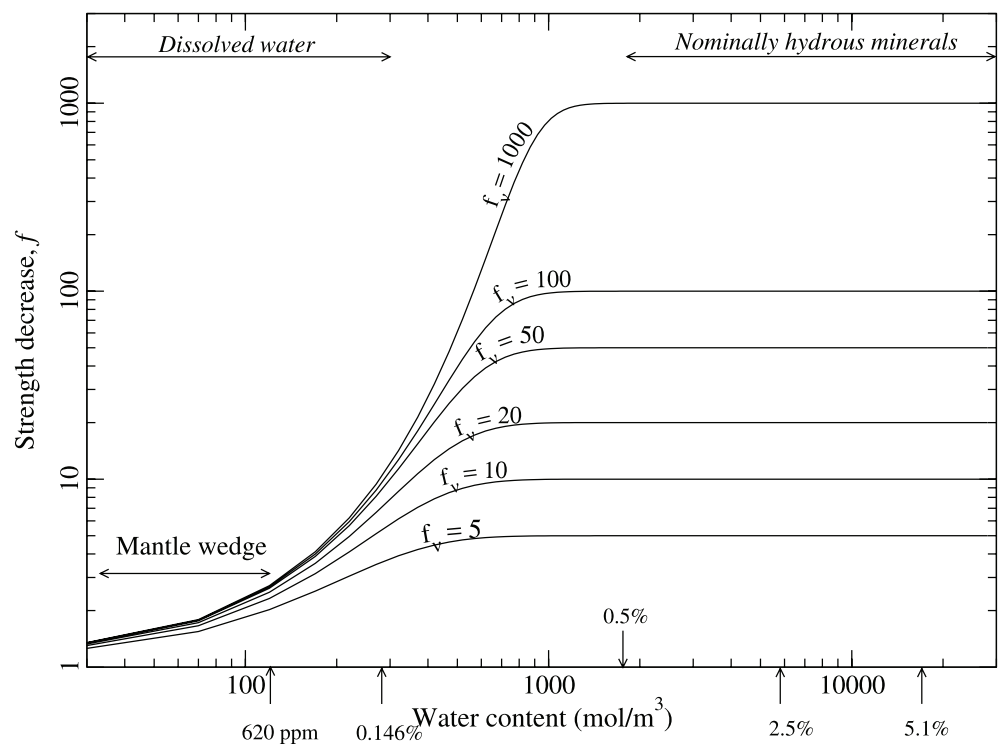

Figure 3. Modeled strength reduction as a function of water content ( $f$, equation (3a)(3b)) for different values of $f_{v}$. Note that the water content scale is displayed in mol. $\mathrm{m}^{-3}$, but corresponding values in weight percent are indicated by arrows.

ably due to the significantly lower grain size of amphibole that helps concentrating shearing in amphibole-rich layers [Altenberger, 1997]. Moreover, Drury et al. [1991] note that for temperature lower than $\sim 950^{\circ} \mathrm{C}$, strain localization in some peridotite massifs appears in hydrated mylonites. Reaction induced softening is then related to (1) the fine grain polyphase formation and (2) the appearance of weak silicates such as amphibole, phlogopite, chlorite, talc, and antigorite, that control the rheology of the mylonite zone. The peridotite deformation mode may thus be linked to the formation of nominally hydroxylated minerals. Our parameterization of the water content effect on rheology does not at all pretend to induce shear localization linked with grain size reduction and reaction induced softening. We only parameterize a possible bulk peridotite strength reduction associated with the formation of hydrous phases.

\subsection{Code and Computation Mesh}

[20] Simulations are performed using an Eulerian code of thermomechanical convection [Christensen, 1984, 1992], based on finite elements to solve the equations of energy, continuity, and momentum on a non-deforming grid. The chemical composition (crust/mantle) is defined in the simulation box through tracers, that are initially uniformly distributed across the grid, and advected along with the velocity field (with a four order Runge-Kutta scheme) [Van Keken et al., 1997]. Markers are scattered one every $1.02 \mathrm{~km}$ in both directions. The convective box is discretized by $340 \times 90$ nodes, that are not regularly spaced across the box. $x$ and $z$ spacings are small in the subduction plane and mantle wedge area $(2.85 \mathrm{~km}$ and $2.26 \mathrm{~km}$, respectively), whereas they are of $10.24 \mathrm{~km}$ and $9.48 \mathrm{~km}$, respectively, in the largest mesh. Both the spatial discretization of the $2220 \mathrm{~km}$ wide and $555 \mathrm{~km}$ deep simulation box and the tracer density have been validated in a previous study [Arcay et al., 2005].

\section{Water Softening Effect on the Overriding Lithosphere}

\subsection{Hydrated Region Characteristics Above the Dehydrating Slab}

[21] Dehydration reactions (serpentine and chlorite breakdown for the initially serpentinized peridotite layer) inside the slab occur on a wide depth and temperature interval (Figure 4a). This is due to (1) a progressive dehydration of the $15 \mathrm{~km}$ thick serpen-

Figure 4. Effect of the hydrous strength reduction on the mantle wedge flow, with $v=5.3 \mathrm{~cm} / \mathrm{yr}$ : (a) $f_{\nu}=1$; (b) $f_{\nu}=$ 5; (c) $f_{\nu}=10$; (d) $f_{\nu}=20$; and (e) $f_{\nu}=50$. One isotherm (black line) every $200^{\circ} \mathrm{C}$. 
Geochemistry

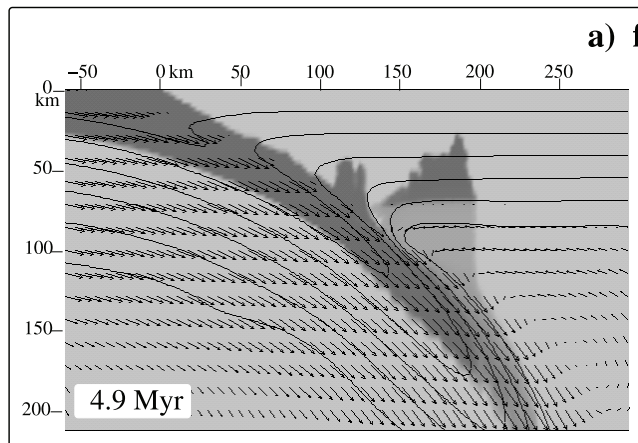

a) $\mathbf{f}_{v}=\mathbf{1}$
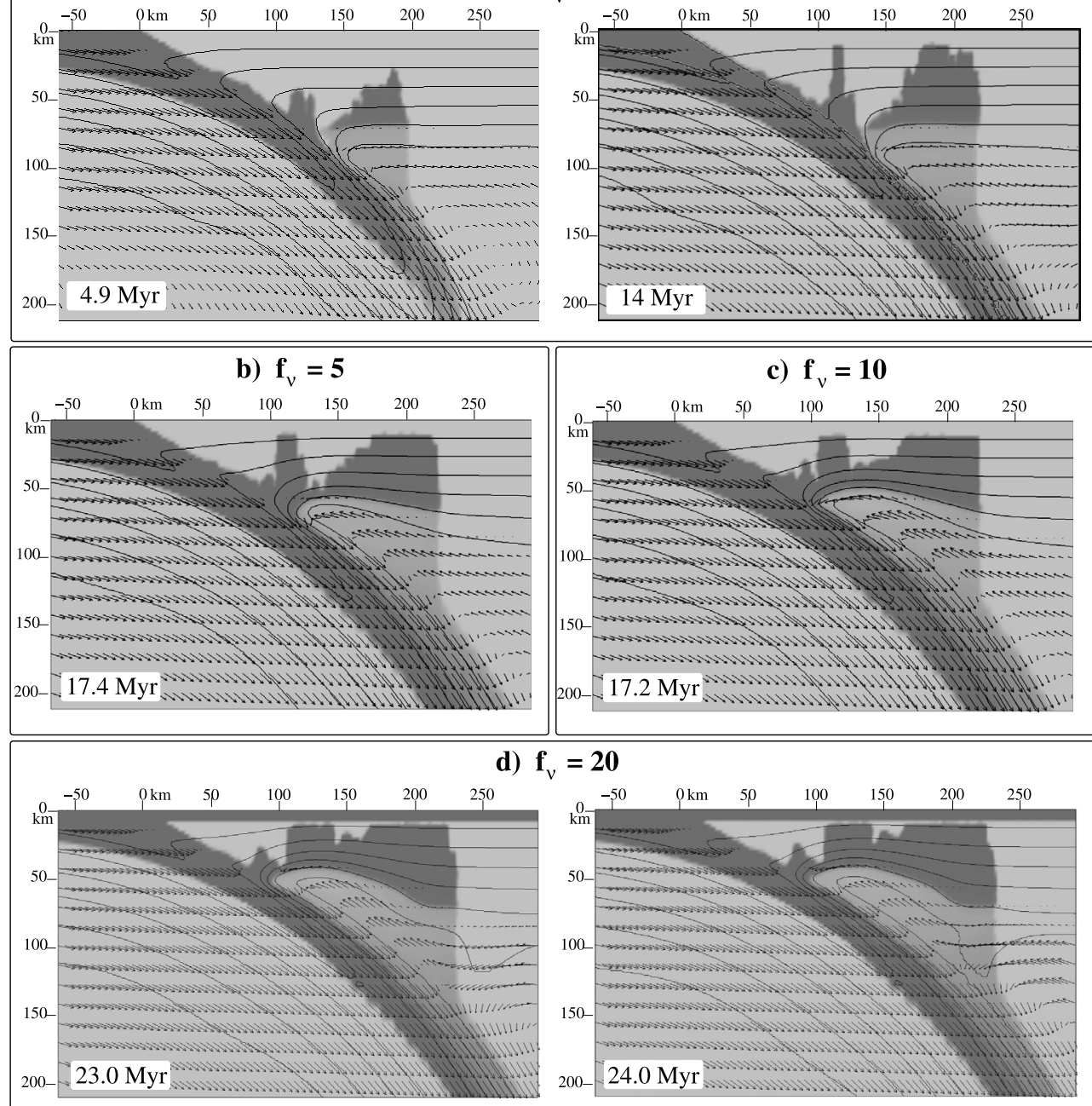

d) $\mathbf{f}_{\mathrm{v}}=\mathbf{2 0}$
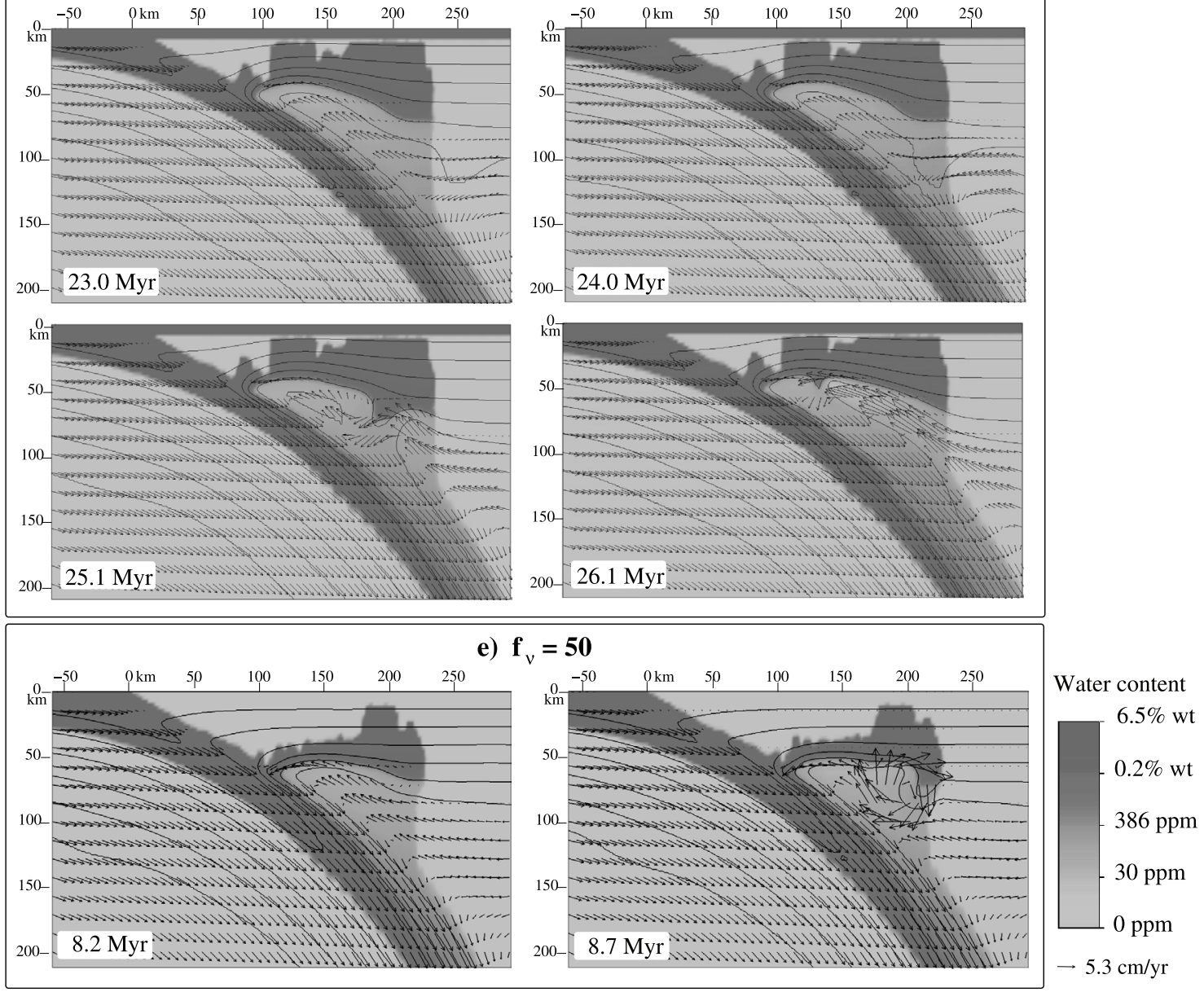

Figure 4 
tinized layer, and (2) the initial cooling in the subduction zone before reaching a steady thermal state, a period during which dehydration fronts progressively deepen with time. The width of the hydrated wedge above the dehydrating slab for $f_{v}=$ 1 increases with the convergence rate (simulations S1a-S1c, Table 1). At $84 \mathrm{~km}$ depth and for a $477 \mathrm{~km}$ long convergence, the hydrated mantle wedge width increases from $55.4 \mathrm{~km}$ for $v=$ $2 \mathrm{~cm} / \mathrm{yr}$ to $88.4 \mathrm{~km}$ for $v=10 \mathrm{~cm} / \mathrm{yr}$. An explanation in terms of dehydration reactions along $P-T$ $-t$ paths in the oceanic crust and in the peridotitic slab is given in detail by Arcay et al. [2005]. Besides, since mantle rocks in the wedge only dissolve a few hundreds of ppm (Figure 2c), the remaining water migrates into the overriding lithosphere. The latter is then quickly hydrated over a significant thickness. The top of the hydrated lithosphere reaches the maximum hydration level as soon as $24.5 \mathrm{Myr}$ after subduction initiation in the $2 \mathrm{~cm} / \mathrm{yr}$ case.

\subsection{Effect of Low Hydrous Strength Reductions $\left(f_{\nu}=5 ; 10\right)$}

[22] To study how low strength reductions $\left(f_{v} \leq\right.$ 10) associated to water content modify the local dynamics in the mantle wedge, the convergence rate is fixed to $5.3 \mathrm{~cm} / \mathrm{yr}$. As presented by Arcay et al. [2005], for strength reductions lower than 10 (simulations S2a and S2b, Table 1), decreasing rock strength with water content enhances the corner flow in the mantle wedge (Figures $4 \mathrm{~b}$ and $4 \mathrm{c}$ ). The strength decrease, $f$, in equation (3a) for high temperature rocks with nominally anhydrous minerals is close to 3.5 or 5.2, respectively, if $f_{\nu}=5$ or 10 , respectively (Figure 3 ). It is sufficient to develop the corner flow that locally thins the upper plate. This enhanced corner flow takes place as soon as the mantle wedge is hydrated (5.5 Myr), and is stabilized until the end of simulation (31 Myr in simulation S2b2) (Figures $4 b$ and 4c). About $14 \mathrm{Myr}$ after subduction initiation, the minimum depth of the $1200^{\circ} \mathrm{C}$ isotherm is $68 \mathrm{~km}$ for $f_{\nu}=5$, while it was $86 \mathrm{~km}$ in the S1a reference case (Figure 4a).

\subsection{Enhanced Erosion of the Overriding Plate for High Strength Reductions $\left(f_{\nu} \geq 20\right)$}

[23] As in previous cases, a larger hydrous strength reduction favors the corner flow development as soon as the mantle wedge becomes water-saturated (Figure $4 \mathrm{e}$ at $8.2 \mathrm{Myr}$, for $f_{\nu}=50$, simulation S2d in Table 1). However, another flow mechanism quickly develops in the wedge, in the form of a convective destabilization of the overriding lithosphere (Figure 4e at $8.7 \mathrm{Myr}$ ). Cold material blobs regularly detach from the upper lithosphere base, and this results in a rapid and strong thinning of the lithosphere. For $f_{v}=50,14.2 \mathrm{Myr}$ after subduction onset, i.e., 5.5 Myr after the convective destabilization onset, the minimum depth of the $1200^{\circ} \mathrm{C}$ isotherm is only $42 \mathrm{~km}$ in the upper plate. Furthermore, the lithosphere erosion by small scale convection does not stay confined near the subduction plane, but takes place over a width of $104 \mathrm{~km}$ (between 112 and $216 \mathrm{~km}$ away from the trench at $14.2 \mathrm{Myr}$ ). For $f_{\nu}=100$ and 1000 (simulations S2e and S2f), we observe the same phenomenon but the upper plate erosion is quicker.

[24] The simulation with $f_{\nu}=20$ first evolves as the simulations with $f_{v}=5$ or 10 , with a well developed and stable corner flow in the mantle wedge (Figure $4 \mathrm{~d}$ at 23 and $24 \mathrm{Myr}$ ). However, at some point (25.1 Myr), convective destabilization is triggered (Figure 4d) and then sustained until the simulation end. The reason for this sudden triggering is not clear. Possibly, a small scale thermal perturbation traveling trenchward at the base of the upper plate and entering the mantle wedge at 24.5 Myr might have driven the first blob detachment (Figure 4d, 1st and 2nd pictures). Once started, convective destabilization of the overriding plate is self-sustained by the low strength and large thermal gradients on the border and top of the eroded area. The large time delay in the convective destabilization onset and its casual appearance suggest that the strength reduction $f_{\nu}=20$ corresponds to the limit between stable corner flow domain $\left(f_{\nu}=5,10\right)$ and convective destabilization domain $\left(f_{v}=50,100,1000\right)$.

\subsection{Parameters Governing the Eroded Region Location}

[25] We study here the relationship between the location of the eroded lithosphere and that of the slab dehydration reactions, for different slab thermal structures and dip angles. The dip angle determines the mantle wedge opening and hence the local heating induced by asthenospheric flow. The slab thermal state is mainly controlled by the product of the incoming plate age, fixed in our simulations to $\sim 100 \mathrm{Myr}$, and its subduction rate. Along the subduction plane, high subduction velocities will induce, on one hand, a more efficient advection of cold materials, but, on other hand, a higher heat dissipation. As a consequence, the 

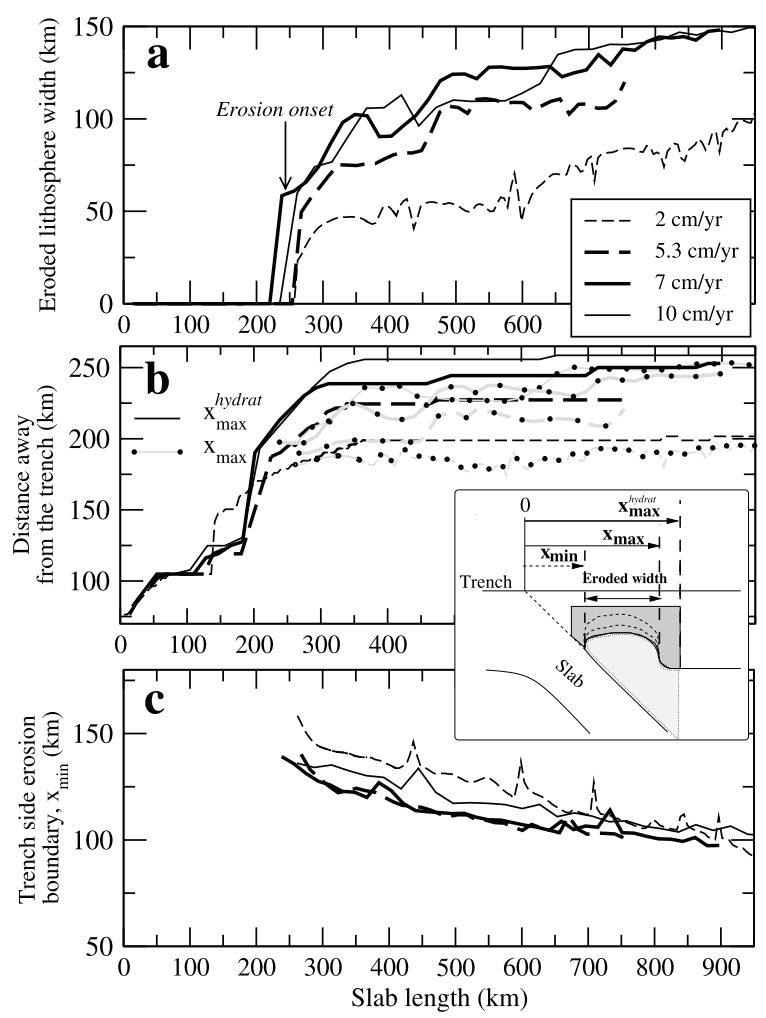

Figure 5. Effect of the convergence velocity, $v$, on the lithosphere hydrated and eroded area geometry. (a) Eroded width of the upper plate during subduction, as a function of the subducted slab length, for different $v$ values. (b) Maximum extent of the lithospheric hydrated area, $x_{\max }$ hydrat (dark lines), and of the lithospheric eroded area, $x_{\max }$ (gray lines with full circles), as a function of the subducted slab length. (c) $x_{\min }$ location as a function of the subducted slab length.

eroded region location as a function of the convergence rate and the initial subduction dip angle is studied in the next two subsections.

\subsubsection{Convergence Rate Influence}

[26] To study the convergence velocity effect on the hydrated upper plate thermal erosion, we fix the maximum hydrous strength reduction, $f_{v}$, to 50 , and test different values of the convergence rate, $v$ $(2,5.3,7$, and $10 \mathrm{~cm} / \mathrm{yr}$ in simulations $\mathrm{S} 3 \mathrm{a}, \mathrm{S} 2 \mathrm{~d}$, $\mathrm{S} 3 \mathrm{~b}$, and S3c, Table 1). We define the vertical erosion rate as the values of $\frac{d z_{\text {lith }}}{d t}$, where $z_{\text {lith }}$ is the upper lithosphere thickness and $t$ is the time. We first find that the vertical erosion rate is independent of the convergence rate. As the convergence rate affects the corner flow velocity, this implies that the corner flow in the mantle wedge has no significant influence on the upper plate erosion process.
[27] On the contrary, the convergence rate affects the eroded region width by modifying the subducting plate thermal structure. The eroded area is bounded by the $x$-locations of the $1000^{\circ} \mathrm{C}$ isotherm at mid depth between its eroded and non eroded depths: $x_{\min }$, on the trench side, and, $x_{\max }$, on the backarc side (see sketch in Figure $5 \mathrm{~b}$ ). We do not use the depth of the 1200 or $1100^{\circ} \mathrm{C}$ isotherms, which may better represent the lithosphere base, because both are sporadically disturbed by blob detachment when convective destabilization occurs. The eroded width evolution with time, $w(t)=x_{\max }(t)-x_{\min }(t)$, is plotted as a function of the subducted slab length, $l=v \times t$ (Figure 5a). This parameterization allows us here to compare subduction simulations with different convergence rates. Erosion onset then appears for the same slab length, $l_{0} \simeq 225 \mathrm{~km}$. After $950 \mathrm{~km}$ of convergence, the lithosphere eroded width still slightly increases.

[28] The maximum extent of the eroded area $\left(x_{\max }\right)$ is directly controlled by the backarc limit of the lithospheric hydration front, $x_{\max }^{\text {hydrat }}$. The temporal evolution of $x_{\max }^{\text {hydrat }}$ results from the time integration of the slab dehydration front locations. Therefore $x_{\max }^{\text {hydrat }}$ increases as long as the dehydration reactions deepen in the slab, and remains stable when slab dehydration reactions rise within the slab or stabilize (for subducted lengths greater than $\sim 350 \mathrm{~km}$, Figure $5 \mathrm{~b}$ ). As a result, the maximum extent away from the trench of the upper lithosphere hydration varies with the slab thermal structure and thus with the convergence rate. Finally, the backarc extent of the eroded area, $x_{\max }$, closely follows the temporal evolution of $x_{\max }^{\text {hydrat }}$ and thus asymptotically reaches the furthest location of the hydration front (Figure 5b). On the other hand, the trenchward extent of the eroded lithosphere, $x_{\min }$, gets regularly closer from the trench, at a pace that depends more on the subducted length than on the convergence velocity (Figure $5 \mathrm{c}$ ). This progression toward the trench results from a balance between, (1) cold material advection along the slab movement and cooling of the wedge from above by conduction, (2) heat advection in the wedge tip by corner flow and conductive heating across the eroded lithosphere boundary. This results in a slow rising of the wedge tip along the subduction plane that progressively increases the eroded width.

\subsubsection{Dip Angle Influence}

[29] In the present model, the slab dip angle is free to evolve as a function of the (somewhat complex) system force balance. Therefore we cannot directly 


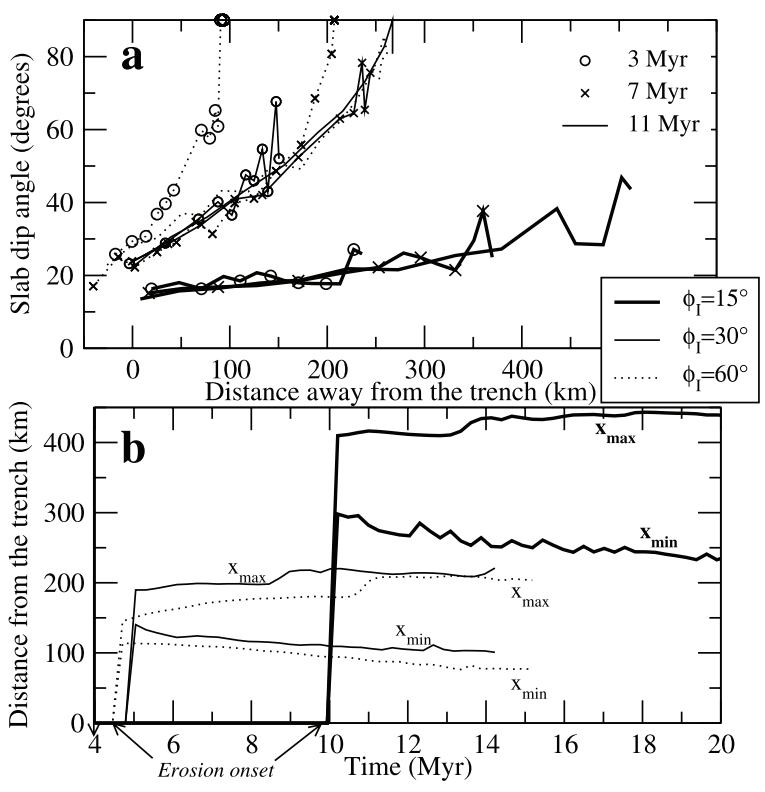

Figure 6. Effect of the initial dip angle, $\phi_{I}$, on the subduction and eroded area geometry. (a) Slab dip angle as a function of the distance from the trench for different times. (b) Evolution of the eroded area location. The eroded area is bounded by $x_{\min }$ and $x_{\max }$ measured with respect to the trench. ( $\mathrm{a}$ and $\mathrm{b}$ ) Subduction plane dip angles, $\phi_{I}$ : thick lines, $15^{\circ}$; thin lines, $30^{\circ}$; dotted lines, $60^{\circ}$.

set the dip angle and study its influence. We choose to modify it by testing three different values for the initial dip angle, $\phi_{I}$, of the weak zone: $15^{\circ}, 30^{\circ}$, and $60^{\circ}$. The convergence rate is set to $5.3 \mathrm{~cm} / \mathrm{yr}$ and the maximum hydrous strength reduction, $f_{v}$, is 50 .

[30] First, let us briefly present how the initial angle of the subduction plane modifies the slab dip angle (Figure 6a). As the elastic rheology is not taken into account in our simulations, the subducting plate undergoes irreversible deformations, dissipating mechanical energy, when it bends and crosses the trench. The slab acquires at the trench an irreversible radius of curvature, meaning that the slab dip angle is zero at the surface and increases progressively with depth, with large (small) curvature radii yielding a low (strong) dip angle increase with depth. The curvature radius is a consequence of the force system equilibrium and may vary with time, for example as the slab pull develops, or as the interplate coupling changes.

[31] We display in Figure 6a the slab dip angle as a function of the distance from the trench for successive simulation durations (3, 7, and $11 \mathrm{Myr}$ ). At subduction initiation, the weak zone dip angle is fixed to $\phi_{I}$. While subduction develops, the weak zone geometry fits to the developing slab radius of curvature, thus shallow slab dip angle near the trench is different from the imposed initial value $\phi_{I}$. If $\phi_{I}$ equals $15^{\circ}$, the subducting lithosphere remains relatively flat (Figure 6a). For $\phi_{I}=30^{\circ}$, the slab is vertical $250 \mathrm{~km}$ away from the trench, but the dip angle remains constant with time. Finally, when $\phi_{I}$ equals $60^{\circ}$, the slab dip angle decreases with time and eventually reaches the slab profile obtained for $\phi_{I}=30^{\circ}$. The two cases $\phi_{I}=30^{\circ}$ and $\phi_{I}=60^{\circ}$ are therefore equivalent.

[32] As expected, the slab dip angle significantly modifies the erosion location in overriding plate. Figure $6 \mathrm{~b}$ displays for $\phi_{I}=15^{\circ}$ and $\phi_{I}=60^{\circ}$, the lateral limits of the eroded region with respect to the trench, $x_{\min }$ and $x_{\max }$ (sketch in Figure 5). For $\phi_{I}=30^{\circ}$ or $60^{\circ}$, the eroded lithospheric region is located between $90 \pm 11 \mathrm{~km}$ and $212 \pm 8 \mathrm{~km}$ away from the trench, 14.3 Myr after subduction onset. On the contrary, for a lower dip angle, the eroded region is located further away from the trench (between $235 \mathrm{~km}$ and $441 \mathrm{~km}$ away from the trench at $21 \mathrm{Myr}$ ). Note that a low dip angle induces a delay of the convective erosion onset. In both cases $\phi_{I}=60^{\circ}$ and $\phi_{I}=15^{\circ}$, dehydration reactions occur approximatively at the same depths because rocks follow similar $P-T$ paths. Therefore, for a lower dip angle, a greater amount of convergence is needed to reach dehydration depths, and the dehydration reaction locations are shifted away from the trench.

\subsection{Accurate Measures of the Overriding Plate Thermal Erosion}

[33] To quantify the rate of the overriding plate thermal erosion, we measure as a function of time the eroded thickness of the overriding plate for different hydrous strength reductions, $f_{v}$ (Figure 7a). For all tested $f_{\nu}$, the erosion process begins by corner flow thinning, which appears with a relatively uniform delay with respect to subduction initiation (between 3.7 and 4.2 Myr). Although the upper lithosphere erosion processes are not the same if $f_{\nu}$ is lower or greater than 20 (see above), all curves in Figure 7a globally reflect the same behavior. The corner flow erosion phenomenon cannot be distinguished from the convective erosion mechanism. This may suggest that both mechanisms are linked. Figure $7 \mathrm{~b}$ shows that the duration $\Delta t_{1}$, necessary to erode a $15 \mathrm{~km}$ thick lithospheric layer, decreases while $f_{v}$ increases. 


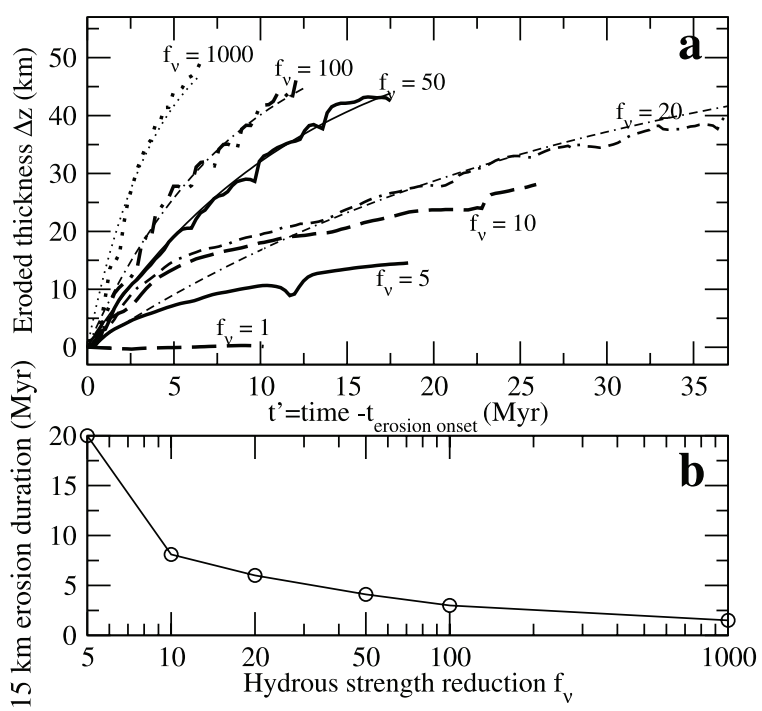

Figure 7. Measurement of the hydrated lithosphere thermal erosion. (a) Eroded thickness in subduction experiments (simulations S1a, S2a, S2b2, S2c, S2d, $\mathrm{S} 2 \mathrm{e}$, and S2f in Table 1) as a function of time since erosion onset. Thick lines, results of numerical simulations; thin lines, fit of experimental results by an exponential curve (discussed in section 4.3). $t_{C}$ estimates: $29.4 \mathrm{Myr}\left(f_{\nu}=20\right), 12.5 \mathrm{Myr}\left(f_{\nu}=50\right), 8.5$ $\operatorname{Myr}\left(f_{v}=100\right), 4.0 \operatorname{Myr}\left(f_{v}=1000\right)$. (b) Duration necessary to remove a $15 \mathrm{~km}$ thick bottom layer of the upper plate as a function of $f_{v}$ in subduction experiments. ( $a$ and b) The eroded thickness is defined as the minimum depth of the $1000^{\circ} \mathrm{C}$ isotherm in the hydrated area minus its initial depth $(67 \mathrm{~km})$.

Therefore the vertical erosion process is mainly controlled by $f_{\nu}$.

[34] In our simulations, lithospheric convective destabilization is different from classical small scale convection, for three basic reasons. First, when the viscosity is strongly temperature-dependent, classical small scale convection is triggered in a thin unstable sublayer at the base of the lithosphere, characterized by a small effective temperature drop, $\Delta T_{\text {eff }}$, defined as $\Delta T_{\text {eff }}=2.24 \times$ $\left(-\frac{\partial \ln v}{\partial T}\right)^{-1}$ [Davaille and Jaupart, 1994; Grasset and Parmentier, 1998; Dumoulin et al., 1999; Solomatov and Moresi, 2000]. In our study, $\Delta T_{\text {eff }}$ would be approximately equal to $250 \mathrm{~K}$. However, here the temperature drop, $\Delta T_{u}$, across the unstable sublayer is much larger than $\Delta T_{\text {eff. }}$ This will be discussed more precisely in section 4.4. Second, the erosion durations are much smaller than expected from classical small scale convection. For convective removal of a thickened continental lithosphere, driven by a classical temperature drop, $\Delta T_{\text {eff }}$, the erosion duration necessary to recover the equilibrium thickness, $z_{e q}$, is of the order of the conductive time scale, $z_{e q}^{2} / \kappa$ [Morency et al., 2002]. This results in an erosion duration of the order of one hundred Myr, whereas, the erosion durations are here lower than 20 Myr. Third, in our experiments, convection cells appear in a mantle wedge, where both the corner flow and the geometry differ from the usual boundary conditions of small scale convection.

[35] To better understand whether the erosion duration is related to the corner flow dynamics or to the particular strength structure of the hydrated lithosphere, we study in the following section the evolution of the hydrated lithosphere thermal structure without subduction.

\section{Water Softening Effect Without Subduction}

\subsection{Simulation Setup}

[36] The simulation setup for studying the lithosphere/asthenosphere interaction in the presence of water is almost identical to the subduction model, except that, at the surface, we impose a no slip boundary condition. We assume water-saturation for rocks included in a rectangular region, whose dimensions reproduce the hydrated mantle wedge geometry $(140 \mathrm{~km}$ wide and $180 \mathrm{~km}$ deep underneath the minimum hydration depth of $11 \mathrm{~km}$, Figure 8a). As in subduction cases, both asthenosphere and lithosphere are thus hydrated. Water contents of each tracer initially located inside this region are given by Schmidt and Poli's [1998] diagram (Figure 2b), as a function of $P$ and $T$. Since, during subduction, slab dehydration continuously hydrates mantle wedge rocks, we here continuously impose water saturation (depending on local $P, T$ conditions) in the hydrated rectangle. Simulations performed without subduction are presented in Table 3.

\subsection{Low Water Softening Cases $\left(f_{\nu} \leq 20\right)$}

[37] For $f_{v} \leq 20$, no convective destabilization occurs, even if simulations are performed until 120 Myr (simulations S6a to S6c in Table 3). The lithosphere even slightly cools and thickens with time, due to surface cooling by conduction. For $f_{\nu}=20$, the lithosphere evolution contrasts with that obtained for the same strength reduction in a subduction setting, which shows convective destabilization after some time delay (section 3.3). To understand the origin of this discrepancy, it is 


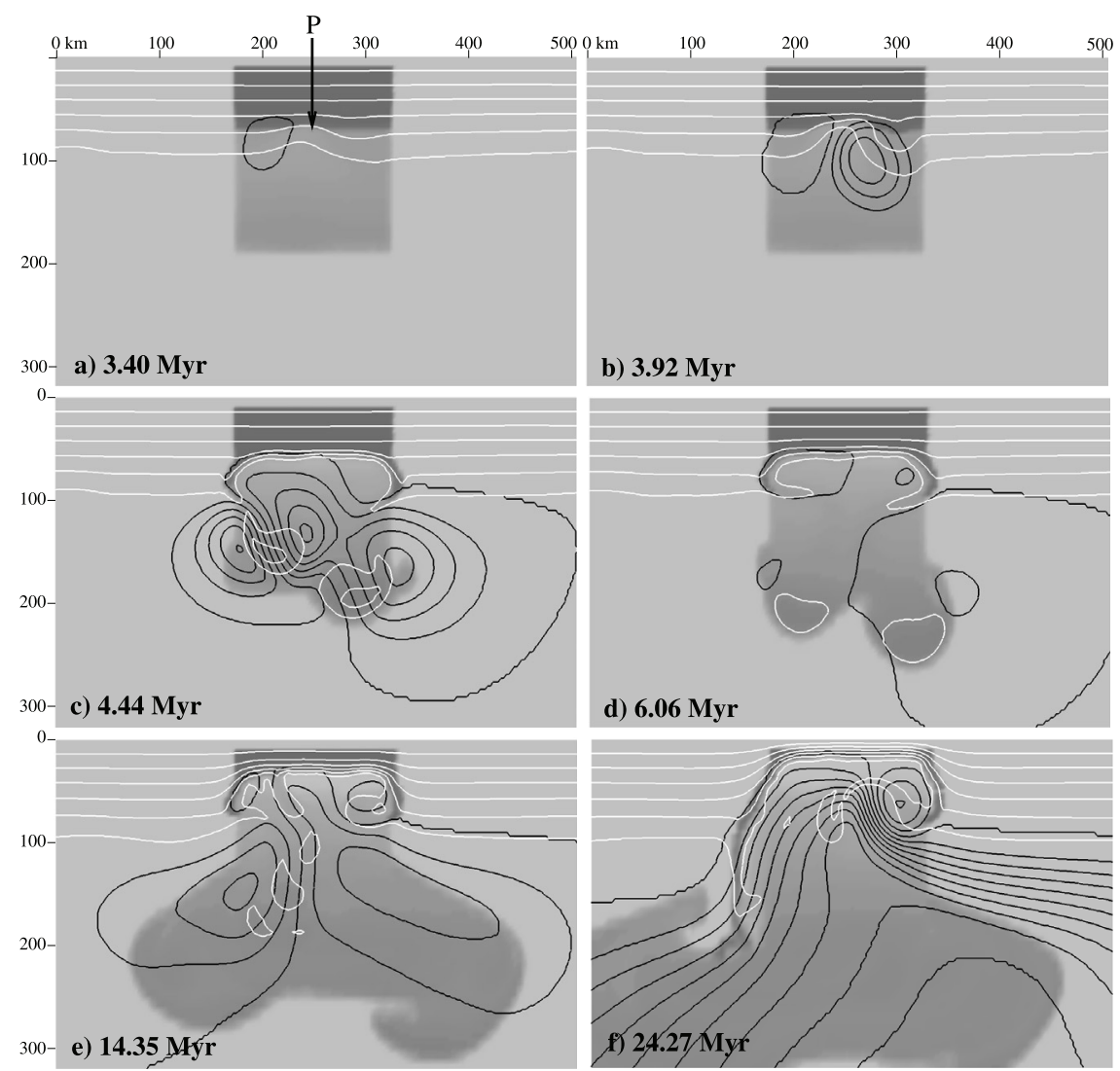

Figure 8. Effect of the water content on the lithosphere structure without subduction, for a maximum hydrous strength reduction $f_{\nu}=50$. Close-up on the hydrated area. One isotherm is displayed every $200^{\circ} \mathrm{C}$ (white line), and one iso-stream function is displayed every $0.2 \mathrm{~cm}^{2} \cdot \mathrm{s}^{-1}$. See Figure 4 for the gray color scale.

important to recall that the rheology employed here is non linear. In a subduction setting, although the strength reduction for $f_{v}=20$ is small, it is sufficient to enhance strain localization in the wedge tip and, as a following, to enhance the corner flow and deformation rates in the wedge. Because of the non linear rheology, rocks viscosities in the mantle wedge are thus decreased by a power law and, together with the presence of an initial thermal perturbation (section 3.3), promote small scale destabilization of the overriding lithosphere. On the contrary, no background corner flow deformation occurs in the simulation performed without plate tectonics. This strengthens the idea that the hydrated lithosphere structure associated to $f_{\nu}=20$ may correspond to the limit between the domains of mechanical stability $\left(f_{\nu}<\right.$ $20)$ and convective instability $\left(f_{v}>20\right)$.

\subsection{High Water Softening Degree Cases $\left(f_{\nu} \geq 50\right)$}

[38] The lithosphere/asthenosphere interaction evolution is exhibited in Figure 8, for $f_{v}=50$ (simulation S6d in Table 3). While, on average, the lithosphere base slowly cools, a convective instability grows progressively across the hydrated lithosphere (Figures 8a and 8b). Stream lines in Figure $8 \mathrm{a}$ show that it encompasses the layer in the lithosphere containing hydroxylated minerals (above $67 \mathrm{~km}$, dark gray layer in Figure 8). The lithospheric strength of this layer with a water content of 0.5 wt $\%$ (facies "AGOpO" in Figure 2) is significantly reduced. Therefore the layer just above $67 \mathrm{~km}$ behaves like a decoupling level, allowing the development of a small scale instability. This first small scale instability detaches at 4.18 Myr (Figure 8c). Deformations then slow down (Figure 8d), a period during which heat conduction reduces the temperature gradient across the base of the hydrated lithosphere (Figures $8 \mathrm{c}$ and $8 \mathrm{~d}$ ). Heat is conducted toward the surface, while the eroded lithosphere bottom thickens by cooling. When the unstable sublithospheric layer becomes sufficiently thick, a new cold drip forms and falls. This cyclic process (quiescent periods followed by drip detachments) is repeated many times. Drips are often swept 
Table 3. Simulations Without Subduction

\begin{tabular}{lccc}
\hline & Hydrous Strength Contrast $f_{\nu}$ & Erosion Onset & $\Delta T_{u},{ }^{\mathrm{a}}{ }^{\circ} \mathrm{C}$ \\
\hline S6a & 5. & - & - \\
S6b & 10. & - & - \\
S6c & 20. & - & - \\
S6d & 50. & $3.16 \mathrm{Myr}$ & 593 \\
S6e & 70. & $1.28 \mathrm{Myr}$ & 616 \\
S6f & 100. & $1.04 \mathrm{Myr}$ & 638 \\
S6g & 350. & $0 \mathrm{Myr}$ & 713 \\
S6h & 1000. & $0 \mathrm{Myr}$ & 767 \\
\hline
\end{tabular}

${ }^{\mathrm{a}}$ Temperature drop calculated from equation (A2).

along the eroded lithosphere boundaries, that localize downwelling currents due to unstable horizontal density contrasts.

[39] The final eroded lithospheric thickness results from the balance between thinning by regular dripping and thickening by conductive cooling. From $25 \mathrm{Myr}$ until the simulation end (50 Myr), the $1000^{\circ} \mathrm{C}$ isotherm depth oscillates around $11 \mathrm{~km}$, that corresponds to the imposed minimum hydration depth, beyond which we assume the remaining water to be evaporated (see section 2.2.3). Similar evolution are obtained for $f_{v} \geq 100$, but the lithosphere erosion rate increases with $f_{\nu}$. For $f_{\nu}=$ 100 (simulation S6f in Table 3), the first cold material blob falls at $1.56 \mathrm{Myr}$, while for $f_{\nu}=$ 350 or 1000 , erosion starts from the simulation beginning (simulations S6g and S6h in Table 3).

[40] Figure 9a displays the depth evolution of the $1000^{\circ} \mathrm{C}$ isotherm during experiments performed without subduction, for $50 \leq f_{v} \leq 1000$. These curves are fitted with an exponential function: $\Delta z(t)=\Delta z_{\max }\left(\exp \left(-t^{\prime} / t_{C}\right)-1\right)$, where $\Delta z(t)$ is the depth variation of the $1000^{\circ} \mathrm{C}$ isotherm with respect to its initial depth, $\Delta z_{\max }$ is the final eroded thickness, $t^{\prime}$ is the time measured from the erosion onset given in Table 3, and $t_{C}$ is adjusted to fit the simulation results. It quantifies the characteristic duration of erosion.

[41] Values for $t_{C}$ are very low and decrease from 10.7 Myr to $1.9 \mathrm{Myr}$ when $f_{v}$ increases from 50 to 1000. Note that, for $f_{v} \geq 50$, the eroded thickness for cases with or without subduction in Figures 7a and $9 \mathrm{a}$ has similar temporal evolution. Therefore the corner flow has little influence on the erosion process. However, the characteristic durations of erosion in subduction cases are all greater by about 2 Myr than estimates obtained without subduction. We note that, after the first $\sim 20 \mathrm{~km}$ of thinning, erosion curves in both cases are parallel, and would be superimposed if curves in subduction cases were shifted back by $2 \mathrm{Myr}$ in the time axis. In fact, thinning in subduction cases starts progressively due to an enhanced corner flow, before convective destabilization is triggered and becomes the main mechanism of lithosphere thinning. On the other hand, thinning starts abruptly at convective destabilization onset in cases without subduction (Figure 9a). After the onset of convection destabilization, the erosion rates with and without subduction are very close, showing that convective destabilization is not influenced by subduction related flow, but controlled by the strength structure of the hydrated lithosphere.

[42] As a result, we assume that, if subduction simulations were carried on long enough for $f_{v} \geq$
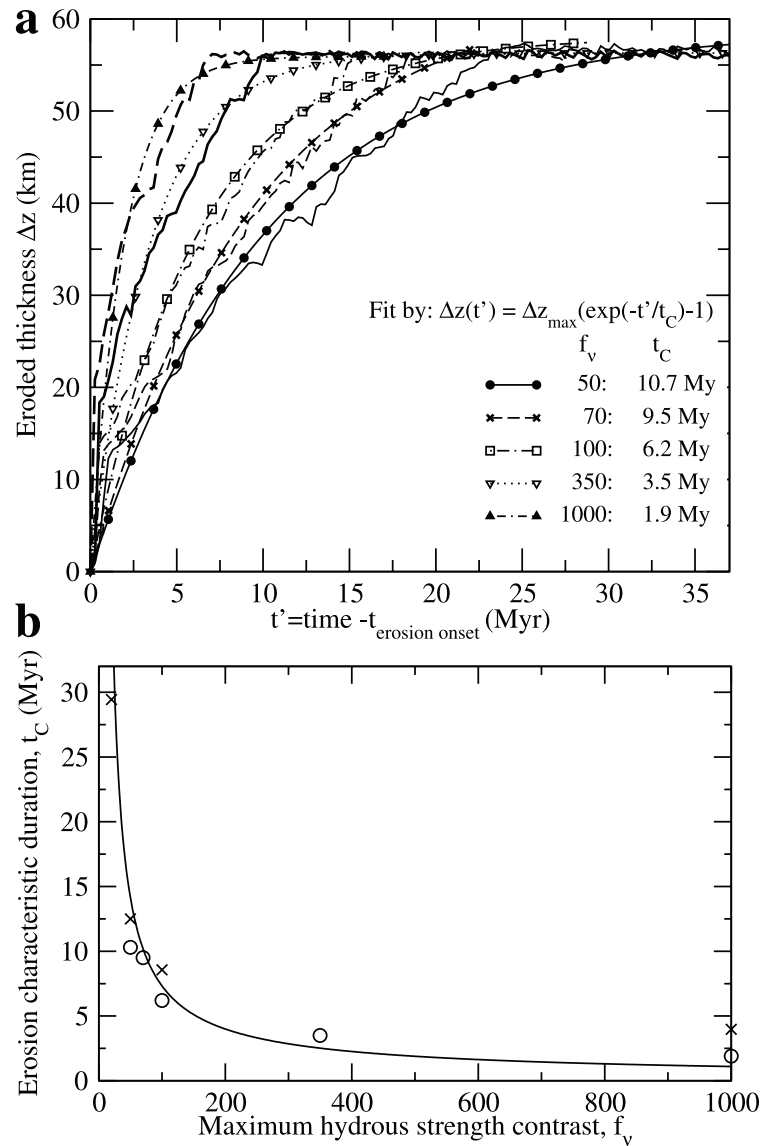

Figure 9. (a) Eroded thickness in convective simulations without plate tectonics (lines without symbols) together with their exponential fit (lines with symbols). $\Delta z_{\max }=-58.2 \pm 4 \mathrm{~km}$. (b) Characteristic duration of erosion as a function of the maximum hydrous strength reduction, $f_{v}$. Simulation without subduction (empty circles) and with subduction (crosses), as indicated in Figure 7a. Relationship predicted with equation (4) (solid line). 


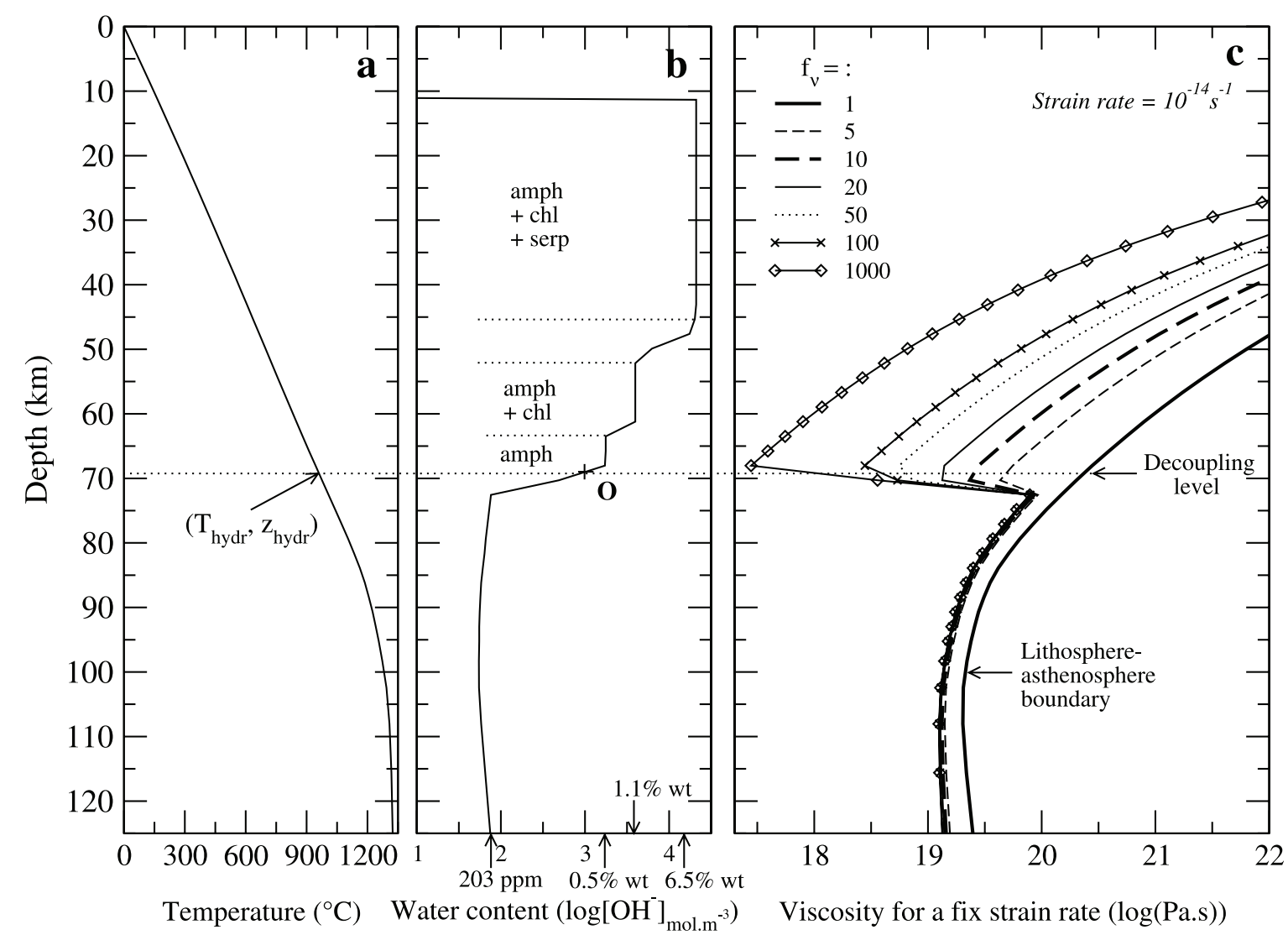

Figure 10. Structure of the hydrated upper lithosphere at the beginning of the simulation, computed at the point $P$ location shown in Figure 8a. (a) Initial lithospheric geotherm. (b) Water content profile in a water-saturated lithosphere, for the initial geotherm displayed in Figure 10a. Logarithmic water contents are expressed in mol.m ${ }^{-3}$, but corresponding values in weight proportions are indicated. (c) Lithospheric viscosities as function of $f_{v}$. Viscosities are computed according to equation (2), using the geotherm and water content profiles displayed in Figures 10a and $10 \mathrm{~b}$, and a reference value for the strain rate: $\dot{\varepsilon}_{r e f}=10^{-14} \mathrm{~s}^{-1} . T_{h y d r}$ and $z_{h y d r}$ are the temperature and depth of appearance of hydrous minerals (point $\mathrm{O}$ ) inside the hydrated lithosphere.

50, the thickness of the upper lithosphere would stabilize at $11 \mathrm{~km}$ depth in the hydrated area, as seen in experiments without subduction.

\subsection{Analysis}

\subsubsection{Conditions for Convective Destabilization Triggering}

[43] The criterion for the onset of convective destabilization of the hydrated lithosphere can here be compared to that studied in detail by Morency and Doin [2004] for the delamination of the mantle lithosphere from the lower crust. In the latter case, the strength profile from the base to the top of the lithosphere is characterized by a viscosity increase as temperature decreases, followed by a sudden viscosity drop at the base of the crust due to the crust lower strength. The crust base acts as a decoupling level that triggers delamination initiation and propagation. Morency and Doin [2004] show that the delamination onset depends on the mantle and crust strength on both sides of the decoupling level.

[44] Here, the initial strength profiles across the water-saturated lithosphere are displayed on Figure 10c. For a non-Newtonian rheology, intrinsic rock strength is defined by the proportionality coefficient $B$ (in $\mathrm{Pa}^{n} . \mathrm{s}$ ) between $\sigma^{n}$ and $\dot{\varepsilon}\left(\sigma^{n}=B \dot{\varepsilon}\right.$ ). However, we choose to represent the strength for a fixed strain rate $\left(\dot{\varepsilon}_{r e f}=10^{-14} \mathrm{~s}^{-1}\right)$ by $B^{1 / n} \dot{\varepsilon}_{r e f}^{\frac{1-n}{n}}$ which has the better known unit of viscosity (Pa.s). It is thus obtained by inserting $\dot{\varepsilon}_{\text {ref }}$ in equation (2). These profiles are obtained with (1) the initial geotherm (Figure 10a), (2) the corresponding water content profile for water-saturated rocks (Figure 10b), and (3) the different values for $f_{\nu}$. 


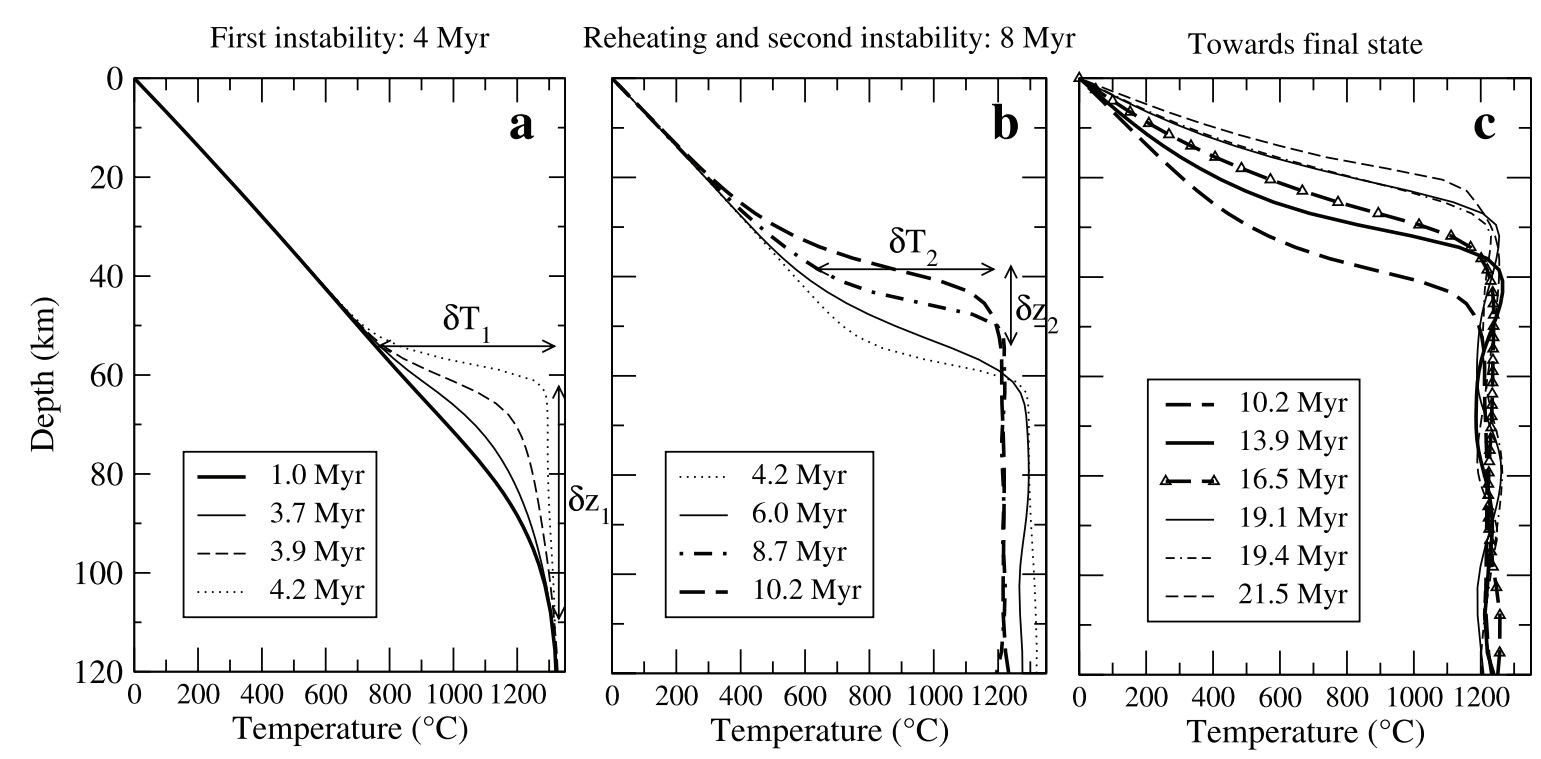

Figure 11. Geotherm evolution during the lithosphere erosion in the $f_{v}=50$ case without subduction. Geotherms are computed in the center of the hydrated region (point $\mathrm{P}$ in Figure $8 \mathrm{a}$ ). $\delta T_{i}$ and $\delta z_{i}$ characterize the unstable sublithospheric layer when cold blobs detach from the lithosphere. (a) Evolution from 1.0 to 4.2 Myr. (b) Evolution from 4.2 Myr to 10.2 Myr. (c) Evolution from 10.2 Myr to 21.5 Myr.

[45] We describe Figure 10c from bottom to top. Below a depth of $72 \mathrm{~km}$ (23 kbar), hydrated mantle rocks are in the wet partial melting domain and dissolve at most $\simeq 280 \mathrm{ppm}$ of water. In this bottom lithospheric layer, below $72 \mathrm{~km}$, the viscosity increases as temperature decreases, with an hydrous strength reduction of a factor less than 2 . Above $68 \mathrm{~km}$ depth, the presence of amphibole increases the water content to $0.5 \mathrm{wt} \%$ (point $\mathrm{O}$ in Figure 10b). This change in water content yields an abrupt viscosity decrease between 72 and $68 \mathrm{~km}$ depth. At depths shallower than $65 \mathrm{~km}$, other hydroxylated minerals (chlorite, talc, serpentine) are stable, thus further increasing the water content. However, they do not, in our simple model, further reduce the rock strength, as a maximum strength reduction is reached for the threshold of $0.5 \mathrm{wt} \%$ (Figure 3). As a consequence, for depths shallower than $65 \mathrm{~km}$, the viscosity only increases as temperature decreases.

[46] Therefore the viscosity structure of watersaturated lithosphere exhibits a local minimum, $\nu_{\text {lith }}^{\min }$, at around $70 \mathrm{~km}$ depth, that we may label as a decoupling level, separated from the asthenosphere by a $30 \mathrm{~km}$ thick more resistant layer. The hydrous strength contrast, $f_{v}$, influences the decoupling level viscosity (Figure 10c). Convective destabilization appears to be triggered when $f_{v} \geq$ 50 , in which cases the decoupling level viscosity is lower than the asthenospheric viscosity. The value $f_{\nu}=20$ corresponds to a threshold between the mechanically stable state of the hydrated lithosphere, and the convectively unstable state (see above).

[47] Destabilization is triggered here as soon as the decoupling level viscosity is sufficiently low. However, Morency and Doin [2004] also showed the influence of the mantle viscosity just below the decoupling level. This implies that destabilization of the overriding lithosphere should here depend not only on the minimum strength inside the hydrated lithosphere, but also, just below it, on the maximum strength of the lithosphere without nominally hydroxylated minerals. The latter depends on the maximum temperature along the geotherm at which nominally hydrous minerals appear in significant proportions. Therefore we test in section 4.5 the influence of the presence of amphibole between 850 and $1000^{\circ} \mathrm{C}$.

\subsubsection{Convective Erosion Process}

[48] Once the conditions for basal lithospheric blob detachment are met, the convective erosion of the overriding lithosphere is a rapid but not instantaneous process. In our simulations, the hydrated lithospheric mantle erosion occurs in a few millions years, with a characteristic duration, $t_{C}$, depending on the hydrous viscosity contrast, $f_{v}$. The geotherm evolution helps understanding how 
the thinning process takes place. Figure 11 exhibits thermal profiles obtained at different times in the $f_{\nu}=50$ case, computed in the center of the hydrated region (point $\mathrm{P}$ in Figure $8 \mathrm{a}$ ). When the first instability detaches from the hydrated lithosphere at about 4.2 Myr, the dripping layer thickness, $\delta z_{1}$, is about $40 \mathrm{~km}$ (defined from the thermal profiles before and after instability detachment). This means that the whole layer located below the decoupling level almost instantaneously (in $0.4 \mathrm{Myr}$ ) disappears. The temperature drop across this unstable sublayer, $\delta T_{1}$, reaches about $550^{\circ} \mathrm{C}$. As described in section 4.3, the erosion process then proceeds as the result from a cyclic phenomenon. Periodic instability detachments from the lithosphere are separated by quiescent periods (Figures $8 \mathrm{~b}-8 \mathrm{e}$ ). This induces a conductive delay between two destabilization steps, and the erosion characteristic duration, $t_{C}$, is a consequence of this heat conduction duration. From the first destabilization to the second one $(\sim 8.7 \mathrm{Myr})$, the destabilized thickness decreases $\left(\delta z_{2} \simeq 16 \mathrm{~km}\right.$, as inferred from thermal profiles, Figure 11b), while the temperature drop across the dripping sublayer remains roughly constant: $\delta T_{1} \simeq \delta T_{2}=\Delta T_{u}$. Finally, the lithosphere thins until the whole hydrated and weakened layer disappears. When a statistically steady state is reached, the geotherm becomes linear inside the lithospheric lid, and convection occurring in a thin hydrated sublayer compensates the cooling of the lid from above. Because water is brought continuously into the lithosphere, this sublayer remains water saturated. It cyclically disappears by dripping induced by hydrous weakening and forms again during lithospheric cooling and thickening.

\subsubsection{Scaling Law for the Characteristic Duration of Erosion}

[49] The thermal and flow description made above is close to classical small-scale convection. However, in classical small scale convection, the effective temperature jump $\left(\Delta T_{\text {eff }}\right)$ driving the sublithospheric convection is of the order of $200^{\circ} \mathrm{C}$, while here the effective temperature drop across the unstable layer, $\Delta T_{u}$, is much larger, because the destabilized layer is here much thicker than ins classical small-scale convection. The temperature drop difference comes from the difference in the lithosphere rheological structure. $\Delta T_{\text {eff }}$ is controlled by the effective viscosity temperature dependence, whereas in our study, the water weakening effect increases the thickness and temperature drop of the sublithospheric unstable layer. Hence the rheolog- ical structure of the upper lithosphere is here a key factor of the hydrated lithosphere evolution. A scaling analysis provides a means to verify that the mechanism of lithosphere thinning in presence of water is well understood. We thus compare estimates of characteristic durations of erosion obtained from numerical simulations to values predicted by a theoretical analysis.

[50] The theoretical analysis is described in Appendix A, but the reasoning is briefly summarized below. We write that the thinning duration derives from the energy balance in the rigid lid, which is heated by an enhanced basal heat flow and cooled by a constant surface heat flow. Both heat flows are assumed to obey scaling laws obtained from small scale convection. However, the bottom heat flow expression takes into account the large temperature drop, $\Delta T_{u}$, and the low minimum viscosity in the decoupling level due to water weakening. Finally, the expression of $\Delta T_{u}$ is obtained by assuming that it corresponds to a viscosity drop of $\exp (2.23)$. The expression of the characteristic duration of erosion, $t_{C}$, derived in Appendix A, is

$$
t_{C}=0.45 \frac{z^{i 2}}{\kappa} \frac{\left(1-\frac{\Delta T_{u}}{T_{a}-T_{s}}\right)^{2}}{C^{-\frac{1}{3}} f_{\nu}^{\frac{1}{2}}\left(\frac{\Delta T_{u}}{\Delta T_{e f f}}\right)^{\frac{4}{3}}-1}
$$

where $z^{i}$ is the lithosphere thickness before erosion, $\Delta T_{u}$ is given in Table 3 , and $C$ is the viscosity contrast due to temperature and depth alone, from the asthenosphere to the base of the layer with hydrous minerals. Other parameters are described in Table 2. The relationship (4) yields predicted values of $t_{C}$ with the same order of magnitude as estimated from numerical simulations without subduction (Figure 9a). A delay of $\sim 2 \mathrm{Myr}$ (see section 4.3) should be added to the value of $t_{C}$ predicted by equation (4) before comparing it to $t_{C}$ estimates from subduction simulations.

\subsection{Influence of Peridotite Mineralogy}

\subsubsection{Peridotite Water Content Grid Without Amphibole}

[51] As described in section 4.4.1, the presence of amphibole until a depth of $70 \mathrm{~km}$ inside the overriding lithosphere, in large proportions (22.1 wt \% in the facies labelled "AGOpO," Figure 2) may be, in our model, the triggering factor of the upper plate thinning. $\mathrm{H}_{2} \mathrm{O}$-content in peridotite as predicted by petrological experiments depends mainly on the molar distribution of main hydrous 
phases, but also, on the amount of minor phases [Iwamori, 2004]. The stability of amphibole strongly depends on $\mathrm{Na}$ concentration in peridotite. To discuss the role of amphibole, we compute a phase diagram together with the water content at saturation for a $\mathrm{Na}$ free peridotite. Pargasitic amphiboles are stable for temperatures until $\sim 1000^{\circ} \mathrm{C}$ and pressures lower than $30 \mathrm{kbar}$, in fertile pyrolite as well as in depleted peridotite [Mengel and Green, 1986; Wallace and Green, 1991; Niida and Green, 1999]. We assume a lherzolite composition for mantle rocks from Ringwood [1975] in which we impose an extremely low $\mathrm{Na}$ content $(0.03 \mathrm{wt} \%)$, in order to limit the formation of amphibole. Phase diagram is calculated using Gibbs free energy minimization method [de Capitani and Brown, 1987] and the database of Holland and Powell [1998] (updated in June 2001), as in Bousquet et al. [2005], in $\mathrm{H}_{2} \mathrm{O}-$ saturated conditions and assuming no melting. We then add the water content dissolved by peridotite in the $P-T$ domains where no nominally hydrous minerals exist, as described in section 2.2.1.

[52] On the new water content grid (Figure 12), the very low proportions of amphibole above $800^{\circ} \mathrm{C}$ at low pressure $(<20 \mathrm{kbar})$ implies a very low watercontent $(0.02 \mathrm{wt} \%)$. Moreover, we note the appearance of clinohumite at high pressures above $6 \mathrm{GPa}$ [Pawley, 2000], as has been observed in peridotite of UHP terranes [Yang, 2003; Katayama et al., 2003]. Clinohumite $\left(2 \mathrm{wt} \% \mathrm{H}_{2} \mathrm{O}\right)$ in this grid overlaps the phase A $\left(4 \mathrm{wt} \% \mathrm{H}_{2} \mathrm{O}\right)$ stability field of Schmidt and Poli [1998] but extends to significantly greater temperatures.

\subsubsection{Influence of Mineralogy on Hydrated Lithosphere Thinning}

[53] Replacing the Schmidt and Poli [1998] lherzolite water content grid (referenced as SP) by that described above (referenced as BC) results in a slight widening of the hydrated and eroded area (Figure 12i, $44 \mathrm{Myr}$ ). This is due to the deepening of the maximum dehydration depth of the serpentinite layer in the subducting slab, from $170 \mathrm{~km}$ (55 kbar) using grid SP to $203 \mathrm{~km}(65.7 \mathrm{kbar})$ using grid $\mathrm{BC}$ (Figures 12a and 12b). The backarc dehydration front location depends on the assumed $P-T$ boundaries of the serpentine/chlorite/phase A stability fields.

[54] Furthermore, due to the very low amphibole proportion at high temperature condition $\left(>850^{\circ} \mathrm{C}\right)$ in grid $\mathrm{BC}$, the deepest domain with a significant water content $(\gg 0.02 \mathrm{wt} \%)$ along the lithospheric geotherm occurs at a depth of $58 \mathrm{~km}$. Therefore the decoupling level depth is $12 \mathrm{~km}$ shallower when using grid $\mathrm{BC}$ than when using grid $\mathrm{SP}$ (points $\mathrm{O}$ and $\mathrm{O}_{2}$ in Figure 12d). As the decoupling level temperature decreases from grid $\mathrm{SP}\left(950^{\circ} \mathrm{C}\right)$ to grid $\mathrm{BC}\left(820^{\circ} \mathrm{C}\right)$, the viscosity on both sides of the decoupling level interface increases. Therefore, whereas a strength contrast $f_{v}=50$ was large enough using grid SP to obtain a decoupling level viscosity lower than the asthenospheric viscosity, for grid $\mathrm{BC}$, strength contrasts of $f_{\nu} \leq 100$ are still too low to yield a decoupling level viscosity of the order of the asthenospheric viscosity. On the other hand, the maximum viscosity in the lithospheric layer below the decoupling level increases by one order of magnitude from $7.6 \times 10^{19} \mathrm{~Pa} . \mathrm{s}$ (grid SP) to $7.3 \times 10^{20}$ Pa.s (grid BC, Figures $12 \mathrm{c}$ and $12 \mathrm{e}$ ). The sublithospheric layer located between the decoupling level and the asthenosphere, which is both stronger and thicker using grid $\mathrm{BC}$ than using grid SP, acts as a mechanically insulating layer.

[55] This is why convective destabilization does not occur for grid $\mathrm{BC}$ and $f_{v}=50$ (Figures $12 \mathrm{f}$ and $12 \mathrm{~g}$ ), and is delayed to $44 \mathrm{Myr}$ after the subduction onset for grid $\mathrm{BC}$ and for $f_{v}=100$ (Figures $12 \mathrm{~h}$ and 12i). The overriding plate thinning by the flow in the wedge tip therefore becomes the main erosion mechanism, although restricted to a corridor along the subduction plane.

\section{Discussion}

[56] The mechanism of convective destabilization of the upper plate presented in this paper reduces the overriding plate thickness on 100 to $200 \mathrm{~km}$ wide areas, depending on the subduction dip angle. This mechanism is independent from the stress state of the upper plate. Therefore it could help explaining the high heat flows that are observed a few hundreds kilometers away from the volcanic arc in compressive subduction zones, such as in the Cascadia subduction zones $\left(80 \mathrm{~mW} \cdot \mathrm{m}^{-2}\right)$ and the Northeast Japan $\left(\simeq 120 \mathrm{~mW} \cdot \mathrm{m}^{-2}\right)$ [Davies and Lewis, 1984; Lewis et al., 1988, 1992; Furukawa and Uyeda, 1989; Furukawa, 1993; Hyndman and Lewis, 1999]. However, the convective erosion mechanism described here is probably unusual as it involves a quick $(<15 \mathrm{Myr})$ and strong $(>80 \mathrm{~km})$ thinning of the hydrated upper plate layer.

[57] Before applying to the Earth subduction zone these extreme values for both characteristic duration of erosion and eroded thickness, one should 


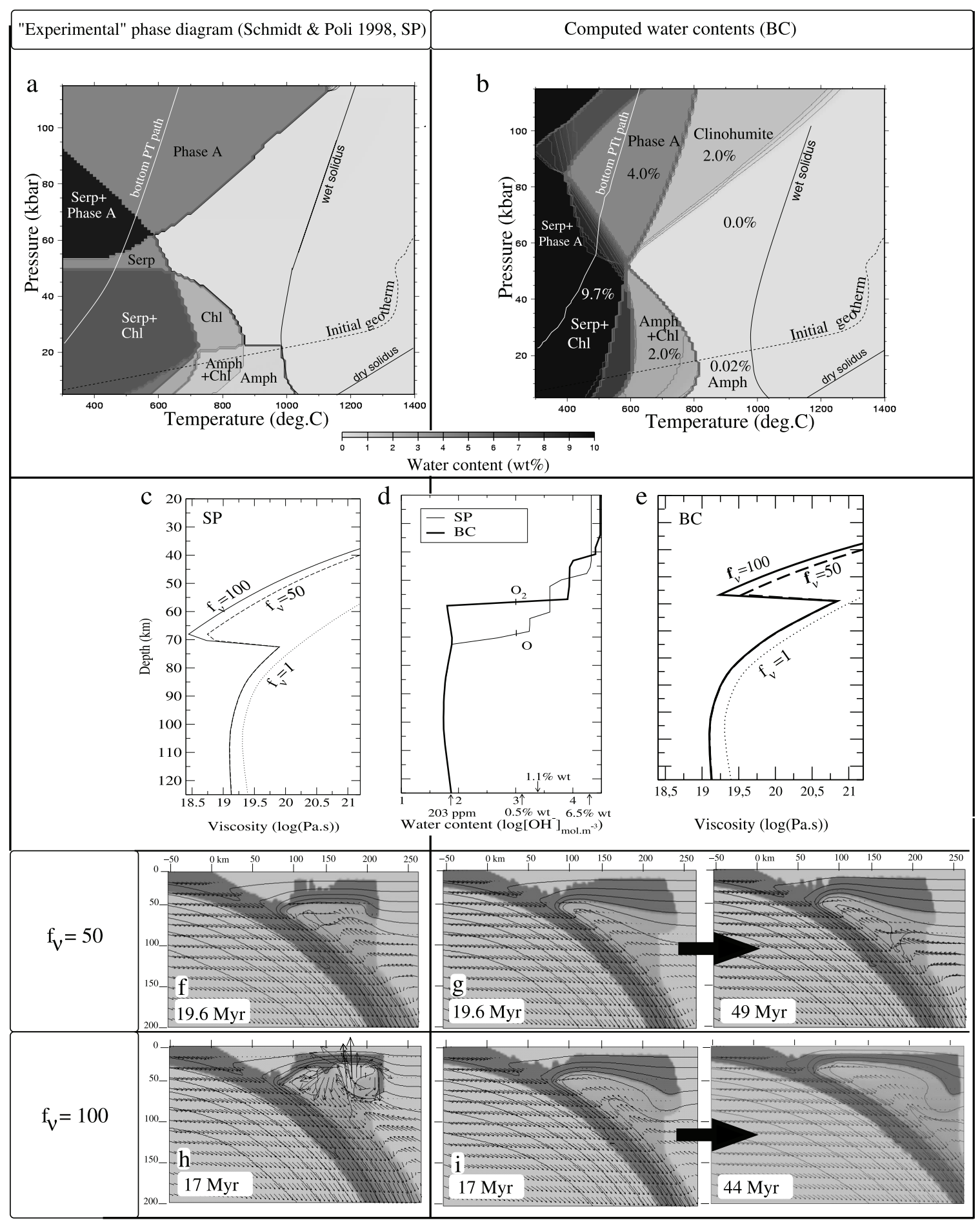

Figure 12. Influence of peridotite mineralogy on the subduction erosion process. (a and b) Water content grid as a function of $T$ and $P$ for lherzolititic compositions and water-saturated conditions, obtained by experimental approach (Figure 12a, Schmidt and Poli [1998], SP) and/or by a thermodynamic calculation (Figure 12b, this study, BC). (d) Water content profiles across the lithosphere for the initial geotherm and the two water content grids. (c and e) Reference viscosity profiles, computed with $\dot{\varepsilon}_{\text {ref }}=10^{-14} \mathrm{~s}^{-1}$, using the initial geotherm and the water content profiles for grid SP (Figure 12c) and grid BC (Figure 12e). ( $\mathrm{f}$ and $\mathrm{h}$ ) Subduction simulations for grid SP. (g and i) Subduction simulations for grid BC. Note the gray color scale indicating water content is the same as in Figure 4. 
take into account in the framework of this model the continental crust in the upper plate and density changes due to hydration. The crust positive buoyancy should restrain the convective removal to the mantle lithosphere. The density reduction of peridotite including amphibole (plus chlorite, plus talc, respectively), is of about $60 \mathrm{~kg} \cdot \mathrm{m}^{-3}\left(110 \mathrm{~kg} \cdot \mathrm{m}^{-3}\right.$, $160 \mathrm{~kg} \cdot \mathrm{m}^{-3}$, respectively), thus cancelling the negative buoyancy of $600^{\circ} \mathrm{C}\left(1100^{\circ} \mathrm{C}, 1600^{\circ} \mathrm{C}\right.$, respectively) colder rocks. As a result, we might expect that, if these density reductions were included in the model, the unstable sublayer in the hydrated overriding plate would be restricted to the layer containing no nominally hydrous minerals. This should limit the temperature drop, $\Delta T_{u}$, across the unstable sublayer and make it independent of the hydrous strength reduction. However, the decoupling level inside the hydrated overriding lithosphere should still act as shown in this work and trigger enhanced small scale convection. Eventually, we guess that the analysis described in Appendix A, and equation (4) should still be valid with smaller $\Delta T_{u}$ values, yielding a clear increase in the characteristic duration of erosion.

[58] Another limitation of our model is the absence of partial melting modeling. Without melt segregation, the combined effect of partial melting and water saturation of the solid peridotite (thanks to constant water flux rising from the dehydrating slab) is likely to decrease mantle strength by about 3 orders of magnitude [Mei et al., 2002]. However, melt extraction has been argued to occur as soon as melt fraction reaches $2 \mathrm{wt} \%$ to $5 \mathrm{wt} \%$ [Gaetani and Grove, 2003]. Moreover, the residual peridotite after melting is refractory, and may be depleted in aqueous fluids. Consequently, the residual peridotite in the mantle wedge may be stiffer than fertile peridotite [Hirth and Kohlstedt, 1996], which may slow down the convective destabilization process. Still, for a constant water flux supplied by slab dehydration, the solid residue may still remain water-saturated after melt extraction [Mei et al., 2002]. Furthermore, even for low melt fractions retained in the solid peridotite ( $2 \mathrm{wt} \%$ [Gaetani and Grove, 2003]), the presence of melt reduces the dynamically recrystallized grain size, and could change the deformation mechanism. This would favor a viscosity decrease of one order of magnitude [Braun et al., 2000]. Finally, the strengthening effect of melt extraction could be cancelled, or melt extraction may still lead to a slight weakening of mantle rocks.
[59] Nevertheless, one prediction of this model, if applicable, is that the lithospheric thinning area is controlled by the hydrated mantle wedge geometry. The latter directly depends on the $P-T$ paths followed by slab particles and where they cross dehydration reactions. While the subducting plate thermal structure is well controlled in our simulations, the water content model is given by the assumed phase diagram, on which significant uncertainties still exist. One discrepancy arises from the nature of the modeled metamorphic reactions, either assumed sharp or allowed to be progressive. In the first case (grid SP above) the slab water content evolution is discontinuous along the serp $\rightarrow$ phase $A+$ op $x+\mathrm{H}_{2} 0$ reaction, whereas in the second case (grid $\mathrm{BC}$ above), the water content decreases progressively across the same metamorphic reaction. The lateral extent of the hydrated mantle wedge also depends on the stability field of high-pressure/low temperature hydrous phases, such as phase A, $10 \AA$ phase, and clinohumite [Pawley and Wood, 1995, 1996; Pawley, 2000; Fumagalli et al., 2001; Poli and Schmidt, 2002; Fumagalli and Poli, 2005]. The $10 \AA$ phase is not included in the mineralogic grids used in this study. If included, they may delay in some cases the dehydration of the top serpentinite layer to greater depth, therefore widening the hydrated wedge.

[60] Finally, the mantle bulk composition, in terms of enrichment or depletion in major and minor oxydes, and in term of water-saturation degree, may vary from a subduction zone to another. Moreover, both kinematic and metamorphic latent heat effects are not taken into account in our model, and phase transitions are assumed not to be metastable. These restrictions may induce a shift between the stability domains of hydrous minerals and the effective dehydration/hydration front locations. On the other hand, if the upper plate thinning mechanism is, as assumed in this study, strongly dependent on the release of slab dehydration fluids and on wedge and overriding lithosphere hydration, the down dip location domain of hydrous phases inside the slab could be investigated by studying in detail the geometry of thermal anomalies along a compressive backarc.

\section{Conclusion}

[61] We perform dynamic and time-dependent simulations of subduction, including an explicit model of slab dehydration and overlying rock hydration. 
The water content effect on rheology is parameterized in a simple way. The influence of rock weakening associated to the hydration of the mantle wedge and overlying lithosphere structure is the following:

[62] 1. For a large strength reduction associated to water content $\left(f_{v} \geq 50\right)$, the upper lithosphere hydration induced by the slab dehydration yields a strong thinning of the overriding plate by local small convection cells. The upper plate erosion develops on a $\sim 150 \mathrm{~km}$ wide area. However, the corner flow is the only process able to thin the upper plate for lower hydrous rock weakening $\left(f_{v} \leq 10\right)$. In these cases, the plate thinning is restricted to a narrow corridor at the mantle wedge tip. For all values of $f_{v}$, the vertical erosion rate obtained in our subduction simulations increases continuously with $f_{v}$.

[63] 2. The eroded area corresponds to the hydrated area within the lithosphere. The eroded geometry thus depends on the slab dehydration front locations governed by, first, $P-T$ paths followed by rock elements inside the slab, second, metamorphic reactions occurring in the diving plate. As a consequence, the location and width of the lithosphere eroded area are related to subduction parameters. High convergence velocities and low dip angles rise both the distance of the eroded region location with respect to the trench and the eroded region width.

[64] 3. The erosion rates obtained in simulations of hydrated lithosphere thinning performed without plate tectonics are identical to these corresponding to subduction experiments. The enhanced erosion of the upper plate during the subduction process is thus a free convection phenomenon, not associated to slab-driven convection. This convective destabilization of the overriding lithosphere is controlled by the strength profile of the upper plate when it hydrates. It is triggered by a $70 \mathrm{~km}$ deep decoupling level, associated to a strong water content increase due to amphibole development. The value $f_{\nu}=20$ may correspond to the threshold between the mechanically stable lithosphere domain and the unstable domain.

[65] 4. The lithospheric decoupling level results from the formation of hydroxylated minerals inside the overriding plate. In our modeling, the decoupling level depth depends on the maximum depth where hydroxylated minerals are stable in sufficient proportions to yield a water content of $0.5 \mathrm{wt} \%$. By computing a water content grid in which the appearance of amphibole is inhibited at $70 \mathrm{~km}$ depth, the decoupling level depth is reduced by $12 \mathrm{~km}$. This inhibits the upper plate destabilization for an hydrous strength contrast $f_{\nu}$ of 50 and delays the convection triggering by about $35 \mathrm{Myr}$ for $f_{v}=100$.

[66] 5. The present mechanism for convective removal does not correspond stricto senso to lithospheric delamination. The mantle lithosphere is not instantaneously removed, but thins progressively due to the repeated action of local convection cells. Nevertheless, erosion characteristic durations, $t_{C}$, remain here lower than 12 Myr. The value of $t_{C}$ as a function of $f_{v}$ is predicted by a scaling law. The analysis made to obtain the $t_{C}-$ $f_{v}$ relationship assumes that the hydrated lithosphere destabilization corresponds to a classical small-scale convection process characterized by high temperature drops across the destabilized lithospheric layer, $\Delta T_{u}$. The sublithospheric layer, defined by the temperature jump $\Delta T_{u}$, and that detaches from the rigid lid, is unusually thick (more than $30 \mathrm{~km}$ thick), which explains the very short duration of the hydrated lithosphere erosion.

\section{Appendix A: Scaling Law Predicting the Characteristic Duration of Erosion}

\section{A1. Temperature Drop $\Delta T_{u}$}

[67] In classical small scale convection, the temperature drop across the unstable sublayer corresponds to a viscosity contrast equal to $\exp (2.23)$ [Davaille and Jaupart, 1993; Grasset and Parmentier, 1998]. $\Delta T_{u}$ is thus defined by the same viscosity ratio across the unstable sublayer:

$$
\frac{\nu_{\text {eff }}\left(T_{a}-\Delta T_{u}, z^{i}-\delta z,\left[O H^{-}\right]^{\text {lith }}\right)}{\nu_{\text {eff }}\left(T_{a}, z^{i},\left[O H^{-}\right]^{a s t h}\right)}=\exp (2.23)
$$

where $T_{a}$ is the asthenospheric temperature, $z^{i}$ is the lithosphere base depth before erosion, $\delta z$ is the unstable layer thickness, $\left[\mathrm{OH}^{-}\right]^{\text {lith }}$ and $\left[\mathrm{OH}^{-}\right]^{\text {asth }}$, respectively, are water contents at the unstable sublayer top and bottom, respectively. Assuming that the thermal gradient in the sublayer before destabilization is equal to the conductive gradient in the lithosphere, $\left(T_{a}-T_{s}\right) / z^{i}$, the sublayer thickness writes as $\delta z=\left(\Delta T_{u} /\left(T_{a}-T_{s}\right)\right) z^{i}$, where $\left(T_{a}-T_{s}\right)$ is the temperature drop across the lithosphere. The reduction in the preexponential parameter, $A_{0}$, associated to the water content change from $\left[\mathrm{OH}^{-}\right]_{\text {lith }}$ to $\left[\mathrm{OH}^{-}\right]_{\text {asth }}$ is equal to 
$f_{v}$. Besides, the thinning mechanism is assumed to occur at a constant dissipation

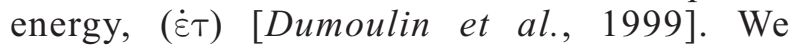
thus define the effective viscosity by $\nu_{\text {eff }}=$ $\left(A_{0}\left(\left[O H^{-}\right]\right)\right)^{\frac{2 n}{n+1}} \exp \left(\frac{2}{n+1}\left(\frac{E_{a}^{m}+V_{a} \rho g z}{R T}\right)\right)(\dot{\varepsilon} \tau)^{\frac{1-n}{1+n}}$. Finally, equation (A1) leads to the following definition of $\Delta T_{u}$ :

$$
\Delta T_{u}=\frac{T_{a}\left(3 \ln \left(f_{v}\right)+4.46\right)}{\frac{E_{a}^{m}+V_{a} \rho g z^{i}}{R T_{a}}-\frac{V_{a} \rho g z^{i}}{R \Delta T_{\text {lih }}}+3 \ln \left(f_{v}\right)+4.46}
$$

The values of $\Delta T_{u}$ calculated with equation (A2) are given in Table 3 as a function of $f_{\nu}$. They are in good agreement with estimates made using geotherm variations in the hydrated area (as shown in Figure 11). Besides, equation (A2) reproduces the temperature drop increase as a function of $f_{v}$ that is observed in simulations.

\section{A2. Energy Balance in the Rigid Lid}

[68] The relationship between $t_{C}$ and $f_{\nu}$ can be then derived from the energy balance of the lithosphere before and after erosion. The variation of the heat contained in the rigid lithosphere (A) must be balanced by the heat provided at its base by convection minus the heat lost by conduction at the surface (B).

[69] The first term (A) taken by unit length is $\Delta E=$ $\rho C_{p}\left(\int_{0}^{z_{q}^{i}} T^{i}(z) d z-\int_{0}^{z_{q}^{f}} T^{f}(z) d z\right)$ ), where $T^{i}(z)$ and $T^{f}(z)$, respectively, are the linear geotherms across the rigid lid at the initial state and at the end of the erosion period, respectively, $z_{q}^{i}$ and $z_{q}^{f}$ are the rigid lid thicknesses at the same respective times. We define $T_{q}$ as the isotherm defining the base of the rigid lid. It is always equal to $T_{q}\left(z_{q}\right)=\left(T_{a}-T_{s}\right)\left(1-\Delta T_{u} /\left(T_{a}-T_{s}\right)\right)$. The initial rigid lid depth, $z_{q}^{i}$, is $z_{q}^{i}=z^{i}\left(1-\Delta T_{u} /\right.$ $\left(T_{a}-T_{s}\right)$ ). Similarly, $z_{q}^{f}=z^{f}\left(1-\Delta T_{u} /\left(T_{a}-T_{s}\right)\right)$, where $z^{f}$ is the lithosphere thickness at the end of the erosion period. $z^{f}$ is fixed to $11 \mathrm{~km}$ by our hydration boundary conditions. Since $z^{i}$ is equal to $100 \mathrm{~km}$, we get $z^{f} \simeq 0.1 z^{i}$. Finally, after some algebra, the heat amount variation, $\Delta E$, writes as:

$$
\Delta E=\frac{0.9}{2} \rho C_{p}\left(T_{a}-T_{s}\right) z^{i}\left(1-\frac{\Delta T_{u}}{T_{a}-T_{s}}\right)^{2}
$$

The second term (B) is $\int_{t 0}^{t 0+t C}\left(q_{b}(t)-q_{s}(t)\right) d t$, where $t_{0}$ is the erosion onset, $q_{b}$ is the heat flow at the rigid lid base, and $q_{s}$ is the surface heat flow.

\section{A2.1. Surface Heat Flow}

[70] To quantify $q_{s}$ during erosion, we verify in a first step that, due to the conductive delay, $q_{s}$ remains constant during the erosion period (for $t_{0} \leq t \leq t_{0}+t_{C}$ ), and equal to its initial value, $k\left(T_{a}-T_{s}\right) / z^{i} \simeq 36 \mathrm{~mW} \cdot \mathrm{m}^{-2}$. The initial surface heat flow is thus equal to the heat flow provided by asthenospheric convection to the lithosphere base before the onset of thermal erosion. This is true because the initial temperature structure in our simulations was itself the result of a long classical small scale convection run computed until a statistically steady state was reached. Therefore we write in a second step that the initial surface heat flux obeys the Nusselt number $(\mathrm{Nu})$ scaling law valid for classical small scale convection and a nonNewtonian rheology [Dumoulin et al., 1999]:

$$
N u=\gamma R a_{B L}^{1 / 3}\left(\frac{\Delta T_{e f f}}{T_{b}-T_{s}}\right)^{4 / 3}
$$

where $T_{b}-T_{s}$ is the temperature drop across the simulation box (Table 2), $R a_{B L}$ is the effective Rayleigh number computed with the effective asthenospheric viscosity $\nu_{\text {eff }}^{\text {asth }}$, and $\gamma=0.178$ in classical small-scale convection. $\Delta T_{\text {eff }}$ is computed from the formula (24) given in Solomatov and Moresi [2000], and is equal to $250 \mathrm{~K}$ in our study. Therefore the surface heat flow can be written as

$$
q_{s}=\gamma_{1} k\left(\frac{\alpha \rho g}{\kappa}\right)^{\frac{1}{3}}\left(\nu_{e f f}^{a s t h}\right)^{-\frac{1}{3}}\left(\Delta T_{e f f}\right)^{\frac{4}{3}}
$$

where $\gamma_{1}$ should be equal to 0.178 if the initial thermal state of the lithosphere is exactly at equilibrium.

\section{A2.2. Basal Heat Flow}

[71] The basal heat flow is obtained by analogy to the scaling law (A4), however, the unstable layer viscosity, parameterized in classical small scale convection by $v^{a s t h}$, is here replaced by the minimum viscosity at the decoupling level, $v_{\text {eff }}^{\min }$. Moreover, since the convective destabilization of the hydrated plate is driven by a large temperature drop across the unstable layer, $\Delta T_{u}$ here replaces $\Delta T_{\text {eff }}$ in equation (A4). The lithospheric basal heat flow, $q_{b}$, finally writes:

$$
q_{b}=\gamma_{2} k\left(\frac{\alpha \rho g}{\kappa}\right)^{\frac{1}{3}}\left(v_{e f f}^{\min }\right)^{-\frac{1}{3}} \Delta T_{u}^{\frac{4}{3}}
$$

As assumptions and modifications made to derive equation (A6) from equation (A4) are relatively 
important, we state that the parameter $\gamma_{2}$ may need to be adjusted to simulations results.

[72] The minimum effective viscosity is: $v_{\text {eff }}^{\min } \simeq$ $\nu_{e f f}^{a s t h} C f_{v}^{-\frac{2 n}{n+1}}$, where $C$ is the viscosity contrast due to temperature and depth alone, from the asthenosphere to the base of the layer with hydrous minerals, $z_{h y d r}$ :

$$
C=\exp \left(\frac{2}{n+1}\left(\frac{E_{a}^{m}+V_{a} \rho g z_{h y d r}}{R T_{h y d r}}-\frac{E_{a}^{m}+V_{a} \rho g z^{i}}{R T_{a}}\right)\right)
$$

where $T_{\text {hydr }}=1220^{\circ} \mathrm{K}$ is the temperature at $z_{h y d r}=$ $68 \mathrm{~km}$ (Figure 10). The basal heat flux then writes:

$$
q_{b}=\gamma_{2} k\left(\frac{\alpha \rho g}{\kappa}\right)^{\frac{1}{3}}\left(C \nu_{e f f}^{a s s h}\right)^{-\frac{1}{3}} f_{v}^{\frac{1}{2}} \Delta T_{u}^{\frac{4}{3}}
$$

\section{A3. $t_{C}$ Expression as a Function of $f_{\nu}$}

[73] Eventually, (B) writes as

$$
\left.\left.\int_{t_{0}}^{t_{0}+t_{C}}\left(q_{b}-q_{s}\right) d t\right|_{2} \gamma_{1} C^{-\frac{1}{3}} \frac{1}{2}\left(\frac{\Delta T_{u}}{\Delta T_{e f f}}\right)^{\frac{4}{3}}-1\right)
$$

By equating equations (A3) and (A9) and noting $\gamma_{2} / \gamma_{1}=\beta$, the scaling law giving the characteristic duration of erosion is:

$$
t_{C}=0.45 \frac{z^{i 2}}{\kappa} \frac{\left(1-\frac{\Delta T_{u}}{T_{a}-T_{s}}\right)^{2}}{\beta C^{-\frac{1}{3}} f_{\nu}^{\frac{1}{2}}\left(\frac{\Delta T_{u}}{\Delta T_{e f f}}\right)^{\frac{4}{3}}-1}
$$

Given the numerous assumptions and approximations made above, Equation (A10) with $\beta=1.0$ (in agreement with $\left.\gamma_{1}=\gamma_{2}=0.178\right)$ predicts relatively well the evolution of $t_{C}$ with $f_{v}$ especially for simulations without plate tectonics that provide a better estimate of the characteristic duration of erosion (Figure 9b).

\section{Acknowledgments}

[74] We would like to thank Fabrice Brunet for helpful discussions. We thank Claire Currie, Satoru Honda, and Peter van Keken for their constructive reviews that helped improve the manuscript. This work was supported by the French national program DyETI 2004, "Dynamique de la subduction." Contribution Geosciences Azur 20060103172246.

\section{References}

Altenberger, U. (1997), Strain localization mechanisms in deep-seated layered rocks, Geol. Rundsch., 86, 56-68.

Andrews, D., and N. Sleep (1974), Numerical modelling of tectonic flow behind island arcs, Geophys. J. R. Astron. Soc., $38,237-241$.
Arcay, D., E. Tric, and M.-P. Doin (2005), Numerical simulations of subduction zones: Effect of slab dehydration on the mantle wedge dynamics, Phys. Earth Planet. Inter, 149, $133-153$.

Bousquet, R., B. Goffé, P. Henry, X. L. Pichon, and C. Chopin (1997), Kinematic, thermal and petrological model of the Central Alps: Lepontine metamorphism in the upper crust and eclogitisation of the lower crust, Tectonophysics, 273, $105-127$.

Bousquet, R., B. Goff, X. Le Pichon, C. de Capitani, C. Chopin, and P. Henry (2005), Comment on "Subduction factory: 1. Theoretical mineralogy, densities, seismic wave speeds, and $\mathrm{H}_{2} \mathrm{O}$ contents," J. Geophys. Res., 110, B02206, doi:10.1029/2004JB003450.

Braun, M., G. Hirth, and E. Parmentier (2000), The effect of deep damp melting on mantle flow and melt generation beneath mid-ocean ridge, Earth Planet. Sci. Lett., 176, 339356.

Christensen, U. R. (1984), Convection with pressure- and temperature-dependent non-Newtonian rheology, Geophys. J. R. Astron. Soc., 77, 343-384.

Christensen, U. R. (1992), An Eulerian technique for thermomechanical modeling, J. Geophys. Res., 97, 2015-2036.

Currie, C., K. Wang, R. Hyndman, and J. He (2004a), The thermal effects of steady-state slab-driven mantle flow above a subducting plate: The Cascadia subduction zone and backarc, Earth Planet. Sci. Lett., 223, 35-48.

Currie, C., R. Hyndman, and K. Wang (2004b), The thermal structure of subduction zone backarcs, Eos Trans. AGU, 85(47), Fall Meet. Suppl., Abstract T23B-1320.

Davaille, A., and C. Jaupart (1993), Transient high-Rayleigh number thermal convection with large viscosity variations, J. Fluid. Mech., 253, 141-166.

Davaille, A., and C. Jaupart (1994), Onset of thermal convection in fluids with temperature-dependent viscosity: Application to the oceanic mantle, J. Geophys. Res., 99, 19,853-19,866.

Davies, E., and T. Lewis (1984), Heat flow in a back-arc environment: Intermontane and Omineca crystalline belts, southern Canadian Cordillera, Can. J. Earth Sci., 21, 715726.

de Capitani, C., and T. Brown (1987), The computation of chemical equilibrium in complex systems containing nonideal solutions, Geochim. Cosmochim. Acta, 51, 2639-2652.

Doin, M.-P., and P. Henry (2001), Subduction initiation and continental crust recycling: The roles of rheology and eclogitization, Tectonophysics, 342, 163-191.

Drury, M., R. Vissers, D. van der Wal, and E. Hoogerduijn Strating (1991), Shear localisation in upper mantle peridotites, Pure Appl. Geophys., 137, 439-460.

Dumoulin, C., M.-P. Doin, and L. Fleitout (1999), Heat transport in stagnant lid convection with temperatureand pressure-dependent Newtonian or non-Newtonian rheology, J. Geophys. Res., 104, 12,759-12,778.

Eberle, M., O. Grasset, and C. Sotin (2002), A numerical study of the interaction between the mantle wedge, the subducting slab, and overriding plate, Phys. Earth Planet. Inter., 134, $191-202$.

Fumagalli, P., and S. Poli (2005), Experimentally determined phase relations in hydrous peridotites to $6.5 \mathrm{GPa}$ and their consequences on the dynamics of subduction zones, J. Petrol., 46, 555-578.

Fumagalli, P., L. Stixrude, S. Poli, and D. Snyder (2001), The $10 \AA$ phase: A high-pressure expandable sheet silicate stable during subduction of hydrated lithosphere, Earth Planet. Sci. Lett., $186,125-141$. 
Furukawa, Y. (1993), Depth of the decoupling plate interface and thermal structure under arcs, J. Geophys. Res., 98, 20,005-20,013.

Furukawa, Y., and S. Uyeda (1989), Thermal state under the Tohoko Arc with consideration of crustal heat generation, Tectonophysics, 164, 175-187.

Gaetani, G., and T. Grove (2003), Experimental constraints on melt generation in the mantle wedge, in Inside the Subduction Factory, Geophys. Monogr. Ser., vol. 138, edited by J. Eiler, pp. 107-134, AGU, Washington, D. C.

Gerya, T., and D. Yuen (2003), Rayleigh-Taylor instabilities from hydration and melting propel 'cold plumes' at subduction zones, Earth Planet. Sci. Lett., 212, 47-62.

Gerya, T., B. Stöckert, and A. Perchuk (2002), Exhumation of high-pressure metamorphic rocks in a subduction channel: A numerical simulation, Tectonics, 21(6), 1056, doi:10.1029/ 2002 TC001406.

Gerya, T., D. Yuen, and E. Sevre (2004), Dynamical causes for incipient magma chambers above slabs, Geology, 32, 89-92.

Grasset, O., and E. Parmentier (1998), Thermal convection in a volumetrically heated, infinite Prandtl number fluid with strongly temperature-dependent viscosity: Implications for planetary thermal evolution, J. Geophys. Res., 103, $18,171-18,181$.

Hasegawa, A., A. Yamamoto, N. Umino, S. Miura, S. Horiuchi, D. Zhao, and H. Sato (2000), Seismic activity and deformation process of the overriding plate in the northeastern Japan subduction zone, Tectonophysics, 319, $225-239$.

Hirth, G., and D. Kohlstedt (1996), Water in the oceanic upper mantle: Implications for rheology, melt extraction and the evolution of the lithosphere, Earth Planet. Sci. Lett., 144, 93-108.

Holland, T., and R. Powell (1998), An internally consistent thermodynamic data set for phases of petrological interest, J. Metamorph. Geol., 16, 309-343.

Honda, S., and M. Saito (2003), Small-scale convection under the back-arc occurring in the low viscosity wedge, Earth Planet. Sci. Lett., 216, 703-715.

Honda, S., and T. Yoshida (2005), Application of the model of small-scale convection under the island arc to the NE Honshu subduction zone, Geochem. Geophys. Geosyst., 6, Q01002, doi:10.1029/2004GC000785.

Honda, S., M. Saito, and T. Nakakuki (2002), Possible existence of small-scale convection under the back arc, Geophys. Res. Lett., 29(21), 2043, doi:10.1029/2002GL015853.

Hyndman, R., and T. Lewis (1999), Geophysical consequences of the Cordillera-Craton thermal transition in southwestern Canada, Tectonophysics, 306, 397-422.

Hyndman, R., C. Currie, and S. Mazzotti (2005), Subduction zone backarcs, mobile belts, and orogenic heat, GSA Today, $15,4-10$.

Iwamori, H. (2004), Phase relations of peridotites under $\mathrm{H}_{2} \mathrm{O}$-saturated conditions and ability of subducting plates for transportation of $\mathrm{H}_{2} \mathrm{O}$, Earth Planet. Sci. Lett., 227, $57-71$.

Katayama, I., A. Muko, T. Iizuka, S. Maruyama, K. Terada, Y. Tsutsumi, Y. Sano, R. Zhang, and J. Liou (2003), Dating of zircon from Ti-clinohumite-bearing garnet peridotite: Implication for timing of mantle metasomatism, Geology, 31, 713-716.

Kelemen, P., J. Rilling, E. Parmentier, L. Mehl, and B. R. Hacker (2003), Thermal structure due to solid-state flow in the mantle wedge beneath arcs, in Inside the Subduction Factory, Geophys. Monogr. Ser., vol. 138, edited by J. Eiler, pp. 293-311, AGU, Washington, D. C.
Kohlstedt, D., H. Keppler, and D. Rubie (1995), Solubility of water in the $\alpha, \beta$ and $\gamma$ phases of $(\mathrm{Mg}, \mathrm{Fe})_{2} \mathrm{SiO}_{4}, J$. Geophys. Res., 100, 17,587-17,602.

Lewis, T., W. Bentkowski, E. Davis, R. Hyndman, J. Souther, and J. Wright (1988), Subduction of the Juan de Fuca Plate: Thermal consequence, J. Geophys. Res., 93, 15,207-15,227.

Lewis, T., W. Bentkowski, and R. Hyndman (1992), Crustal temperatures near the Lithoprobe Southern Canadian Cordillera Transect, Can. J. Earth Sci., 29, 1197-1214.

Lu, R., and H. Keppler (1997), Water solubility in pyrope to 100 kbar, Contrib. Mineral. Petrol., 129, 35-42.

McKenzie, D. (1969), Speculations on consequences and causes of plate motions, Geophys. J. R. Astron. Soc., 18, $1-32$.

McKenzie, D., and M. Bickle (1988), The volume and composition of melt generated by extension of the lithosphere, J. Petrol., 29, 625-679.

Mei, S., W. Bai, T. Hiraga, and D. Kohlstedt (2002), Influence of melt on the creep behavior of olivine-basalt aggregates under hydrous conditions, Earth Planet. Sci. Lett., 201, 491-507.

Mengel, K., and D. Green (1986), Stability of amphibole and phlogopite in metasomatized peridotite under water-saturated and water-undersaturated conditions, in Kimberlites and Related Rocks, edited by J. Ross et al., pp. 571-581, Blackwell Sci., Malden, Mass.

Morency, C., and M.-P. Doin (2004), Numerical simulations of the mantle lithosphere delamination, J. Geophys. Res., 109, B03410, doi:10.1029/2003JB002414.

Morency, C., M.-P. Doin, and C. Dumoulin (2002), Convective destabilization of a thickened continental lithosphere, Earth Planet. Sci. Lett., 202, 303-320.

Niida, K., and D. Green (1999), Stability and chemical composition of pargasitic amphibole in MORB pyrolite under upper mantle conditions, Contrib. Mineral. Petrol., 135, 18-40.

Pawley, A. (2000), Stability of clinohumite in the system $\mathrm{MgO}-\mathrm{SiO}_{2}-\mathrm{H}_{2} \mathrm{O}$, Contrib. Mineral. Petrol., 138, 284-291.

Pawley, A., and B. Wood (1995), The high-pressure stability of talc and $10 \AA$ phase: Potential storage sites for $\mathrm{H}_{2} \mathrm{O}$ in subduction zones, Am. Mineral., 80, 998-1003.

Pawley, A., and B. Wood (1996), The low-pressure stability of phase A: $\mathrm{Mg}_{7} \mathrm{Si}_{2} \mathrm{O}_{8}(\mathrm{OH})_{6}$, Contrib. Mineral. Petrol., 124, 90-97.

Poli, S., and M. Schmidt (2002), Petrology of subducted slabs, Annu. Rev. Earth Planet. Sci., 30, 207-235.

Rauch, M., and H. Keppler (2002), Water solubility in orthopyroxene, Contrib. Mineral. Petrol., 143, 525-536.

Ringwood, A. (1975), Composition and Petrology of the Earth's Mantle, McGraw-Hill, New York.

Schmidt, M., and S. Poli (1998), Experimentally based water budgets for dehydrating slabs and consequences for arc magma generation, Earth Planet. Sci. Lett., 163, 361-379.

Solomatov, V., and L.-N. Moresi (2000), Scaling of timedependent stagnant lid convection: Application to smallscale convection on Earth and other terrestrial planets, Geophys. Res. Lett., 105, 21,795-21,817.

Springer, M., and A. Forster (1998), Heat-flow density across the Central Andean subduction zone, Tectonophysics, 291, $123-129$.

Tsumura, N., S. Matsumoto, S. Horiuchi, and A. Hasegawa (2000), Three-dimensional attenuation structure beneath the northeastern Japan arc estimated from spectra of small earthquakes, Tectonophysics, 319, 241-260.

Turcotte, D., and G. Schubert (1982), Geodynamics: Applications of Continuum Physics to Geological Problems, John Wiley, Hoboken, N. J. 
Van Keken, P., S. King, H. Schmeling, U. Christensen, D. Neumeister, and M.-P. Doin (1997), A comparison of methods for the modeling of thermochemical convection, J. Geophys. Res., 102, 22,477-22,495.

Wallace, M., and D. Green (1991), The effect of bulk rock composition on the stability of amphibole in the upper mantle: Implications for solidus positions and mantle metasomatism, Mineral. Petrol., 44, 1-19.
Wanatabe, T., M. Langseth, and R. Anderson (1977), Heat flow in back-arc basins of the western Pacific, in Island Arcs, Deep Sea Trenches and Back-Arc Basins, Maurice Ewing Ser., vol. 1, edited by M. Talwani and W. Pittman, pp. 137-161, AGU, Washington, D. C.

Yang, J.-J. (2003), Titanian clinohumite-garnet-pyroxene rock from the Su-Lu UHP metamorphic terrane, China: Chemical evolution and tectonic implications, Lithos, 70, 359-379. 